\title{
SURFACE ELECTROCHEMICAL CONTROL FOR FINE COAL AND PYRITE SEPARATION
}

DOE Project No. DE-AC22-89PC89758

$\mathrm{DOE} / \mathrm{PC} / 89758--\mathrm{T} 6$

DE92 010938

Technical Progress Report

October 1, 1991 to December 31, 1991

Prepared by

WARS 81092

Weibai $\mathrm{Hu}$

Qinping Huang

Jun $\mathbf{L i}$

Ximeng Zhu

David M. Bodily

Jun Liang

Tingke Zhong

Milton E. Wadsworth

Prepared for

U.S. Department of Energy

Pittsburgh Energy Technology Center

Pittsburgh, Pennsylvania

\section{DISCLAIMER}

This report was prepared as an account of work sponsored by an agency of the United States Government. Neither the United States Government nor any agency thereof, nor any of their employees, makes any warranty, express or implied, or assumes any legal liability or responsibility for the accuracy, completeness, or usefulness of any information, apparatus, product, or process disclosed, or represents that its use would not infringe privately owned rights. Reference herein to any specific commercial product, process, or service by trade name, trademark, manufacturer, or otherwise does not necessarily constitute or imply its endorsement, recommendation, or favoring by the United States Government or any agency thereof. The views and opinions of authors expressed herein do not necessarily state or reflect those of the United States Government or any agency thereof.

\section{MASTER}




\section{$2+403109$ \\ SURFACE ELECTROCHEMICAL CONTROL FOR FINE COAL AND PYRITE SEPARATION}

DOE PROJECT NO. DE-AC22-89PC89758

Technical Progress Report

October 1, 1991 to December 31, 1991

This technical progress report, prepared in accordance with the reporting requirements of DOE Project No. De-AC22-89PC89758, covers the work performed from October 1, 1991 to December 31, 1991. The ongoing work includes the characterization of coal pyrites, the floatability evaluation of three typical U.S. coal samples, the flotation behavior of coal pyrites, the electrochemical measurement of the surface properties of coal pyrites, and the characterization of species produced at pyrite surfaces.

This report contains three sections, "Transpassive Oxidation of Pyrite", " Flotatation and Electrochemical Pretreatment", and "Flotation Kinetics of Coal and Coal Pyrite". 


\title{
TRANSPASSIVE OXIDATION OF PYRITE
}

\author{
Continuation of Rotating Disk Electrode Study
}

\section{INTRODUCTION}

In the transpassive region, $0.4 \mathrm{~V}$ to $0.8 \mathrm{~V}$ (SCE), aggressive electrochemical oxidation of pyrite occurs. The reaction products in this region are $\mathrm{Fe}(\mathrm{III})$ oxides, sulfate ion and partially oxidized sulfur intermediates. Exposure of pyrite to anodic potentials higher than the transpassive region results in rapid oxidation of sulfur intermediates to sulfate ion. The Fe(III) oxides and sulfur intermediates formed in the transpassive region were reduced to metallic iron and hydrogen sulfide ion during a cathodic scan. During a return anodic scan, surface adsorbed hydrogen sulfide ion was observed to react preferentially with elemental iron forming iron sulfide. The remaining iron was oxidized to ferrous hydroxide. These reactions are characterized by two dominant oxidation peaks, corresponding to ferrous hydroxide (peak 1) and iron sulfide (peak 1a), observed in the region $-0.8 \mathrm{~V}$ to $-0.65 \mathrm{~V}$ (SCE). Initial experiments were conducted using rotating disk electrodes to examine the effect of electrode rotation speed on the formation of peak 1 and peak 1a (1). The effect of rotation speed was markedly different for mineral pyrite compared to coal pyrites. For mineral pyrite, at lower rotation speeds, peak 1 (the ferrous hydroxide peak) was predominant and peak 1a (the iron sulfide peak) was relatively insignificant. As rotation speed increased, peak 1a increased, becoming predominant at $700 \mathrm{rpm}$. For coal pyrites, the effect was less pronounced. Peak 1a also increased slowly with increasing electrode rotation speed, but peak 1 remained predominant up to $2000 \mathrm{rpm}$ and peak $1 \mathrm{i}$ was always much smaller than peak 1 . These characteristics can be correlated with observed flotation 
properties of mineral and coal pyrites after electrochemical alteration. As discussed in a previous report (2), the intensity of peak 1a was directly related to the amount of partially oxidized intermediates of pyritic disulfide ion formed in the transpassive region. The exact intermediates formed have not been determined. Reported intermediates of sulfur are the polysulfides (3). Further oxidation may then form sulfur oxygen intermediate (polythionates) (3) leading to the formation of sulfate ion. This sequence may include some of the following: $\mathrm{S}_{3}{ }^{2}, \mathrm{~S}_{4}{ }^{2}, \mathrm{~S}_{5}{ }^{2}, \mathrm{~S}_{6}{ }^{2}, \ldots \mathrm{S}^{0}, \ldots \mathrm{S}_{\mathrm{n}} \mathrm{O}_{6}{ }^{2}, \ldots \mathrm{SO}_{4}{ }^{2}$. Further, the greater the reaction forming peak 1a, the greater the hydrophobicity and floatability of the pyrite particle. A knowledge of the formation of sulfur and sulfur intermediates, indicated as the magnitude of peak 1a, in the transpassive region is important in better understanding methods for the modification and control of surface properties, hopefully to improve coal/pyrite separation. With this objective, a series of experiments were conducted with mineral and Illinois coal pyrite to elucidate the conditions (oxidation potential, electrode pre-condition time and rotation speed) which leads to enhanced formation of peak 1a.

\section{EXPERIMENTAL}

The electrode and solution preparation, equipment and experimental procedure were the same as described previously $(1,2)$.

\section{RESULT AND DISCUSSION}

\section{Mineral Pyrite:}

In the previous cyclic voltammetry studies $(1,2)$, it was observed that peak 1a (iron sulfide peak) is apparent only for scans reversed at anodic potentials higher than $0.6 \mathrm{~V}$ (the 
transpassive region) under conditions of solution stirring. If the electrode was preconditioned in the transpassive region for a certain time, peak la was greatly enhanced, indicating the magnitude of peak 1a correlated directly with the quantity of sulfur intermediates formed in the transpassive region. It has been also observed that increased formation of sulfur intermediates resulted in decreased formation of ferrous hydroxide, indicated by the decrease in magnitude of peak 1 (ferrous hydroxide peak).

A series of runs at various anodic reversal potential in borate/sulfate solution of $\mathrm{pH}$ 9.2, are shown in Figures 1 and 2 for electrode $\mathrm{rpm}=200$, Figures 3 and 4 for electrode $\mathrm{rpm}=700$, and Figures 5 and 6 for electrode $\mathrm{rpm}=1000$ respectively. The intensity of peak 1a increased with increasing anodic reversal potential and reached the maximum value at about 0.85 to $0.9 \mathrm{~V}$ (the potential range, where the reaction forming partially oxidized sulfur intermediates predominate). Further increase of the anodic reversal potential results in gradually decreasing peak $1 a$ intensity (the potential range where the sulfur intermediates oxidized to sulfate ion predominate). Peak 1a disappears for anodic reversal potentials above 1.1 to $1.2 \mathrm{~V}$ depending on electrode rotation speed. The integrated charge associated with peak 1a versus anodic reversal potential for various electrode rotation speed is shown in Figure 7. The charge of peak 1a increased significantly as rotation speed increased from $200 \mathrm{rpm}$ to $700 \mathrm{rpm}$, but increased only slightly as rotation speed was increased from 700 to $1000 \mathrm{rpm}$. The anodic reversal potential corresponding to maximum peak charge tended to increase as electrode rotation speed increased. Figures 8,9 , and 10 illustrate the relative magnitudes of peak $1 \mathrm{a}$ and peak 1 , for various pre-condition times at a threshold potential of $0.6 \mathrm{~V}$, for electrode rotation speeds 0,200 and $1000 \mathrm{rpm}$. The threshold value of $0.6 \mathrm{~V}$ was selected for the longer time experiments because this potential 
discriminated the reaction leading to the formation of peaks 1 and 1a more clearly. The integrated charge associated with peak 1a for various electrode pre-condition times is shown in Figure 11, for 0,200 and $1000 \mathrm{rpm}$ electrode rotation speeds. The charge increased with increasing electrode pre-condition time and tended to level off after $30 \mathrm{sec}$,, probably indicating the saturation of the surface. Again, the effect of electrode rotation speed is distinct only at low rpm. For speeds higher than $200 \mathrm{rpm}$, the effect is almost negligible. For example similar tests at $700 \mathrm{rpm}$ were essentially the same as for the 200 and $1000 \mathrm{rpm}$ test results.

\section{Illinois Coal Pyrite:}

As for mineral pyrite, a series of runs at various anodic reversal potential were performed on Illinois coal pyrite. The results are shown in Figure 12 for electrode rpm $=$ 200, Figure 13 for electrode $\mathrm{rpm}=700$, and figure 14 for electrode $\mathrm{rpm}=2000$. The integrated charge associated with peak 1a versus anodic reversal potential for various electrode rotation speed is shown in Figure 15. The intensity of peak 1a increased slowly with increasing anodic reversal potential and reached the maximum value at about $0.75 \mathrm{~V}$, which is lower than that for mineral pyrite. The charge associated with peak $1 \mathrm{a}$ is much less than for mineral pyrite. Also,the effect of electrode rotation speed is less pronounced compared to mineral pyrite. Figures 16,17 , and 18 show the increasing magnitude of peak 1a, when the electrode pre-condition time was increased at its threshold potential, $0.4 \mathrm{~V}$ (instead of $0.6 \mathrm{~V}$ for mineral pyrite) for electrode rotation speed $\mathrm{rpm}=0,200$, and 1000 .

The integrated charge associated with peak: 1a versus electrode pre-condition time for various electrode rotation speed is shown in Figure 19. The electrode pre-condition time 
required to obtain the same magnitude of peak 1a is much greater than for mineral pyrite. For rotation speeds greater than $200 \mathrm{rpm}$, the charge associated with peak 1a increased with increasing electrode pre-condition time and reached a maximum value in about 3 to 5 min. The total peak charge was observed to decrease when the pre-condition time was prolonged. Under quiescent conditions, (electrode rpm $=0$ ) after $8 \mathrm{~min}$, the curve (Fig.19) tended to level off. No maximum was found within a $10 \mathrm{~min}$. period.

A comparison of mineral pyrite and Illinois coal pyrite is shown in Figure 20. For mineral pyrite, at lower rotation speeds and anodic scan reversal potential, peak 1 , the ferrous hydroxide peak was predominant and peak 1a, the iron sulfide peak, was relatively insignificant. As rotation speed and/or anodic scan reversal potential increased; the iron sulfide peak increased, becoming predominant at $700 \mathrm{rpm}$, when the anodic scan was reversed at $0.8 \mathrm{~V}$. For Illinois coal pyrite, the iron sulfide peak also increased slowly with increasing electrode rotation speed and/or anodic scan reversal potential, but the ferrous hydroxide peak remained predominant up to $2000 \mathrm{rpm}$. These results are consistent with the enhanced reactivity observed for coal pyrite in the transpassive region compared to mineral pyrite. That is, in keeping with the higher reactivity of coal pyrite. The disulfide ion in coal pyrite is oxidized more readily all the way to sulfate ion with fewer partially oxidized sulfur intermediates.

\section{REFERENCES}

1. W. Hu, Q. Huang, Andrew Riley, X. Zhu, David M. Bodily, J. Liang, T. Zhong and Milton E. Wadsworth, Surface Electrochemical Control for Fine Coal and Pyrite Separation, Department of Energy Technical Progress Report, April 1, 1991 to June 30, 1991, University of Utah, 1991. 
2. W. Hu, X. Zhu, David M. Bodily, and Milton E. Wadsworth, Surface Electrochemical Control for Fine Coal and Pyrite Separation, Department of Energy Technical progress Report, April 1, 1990 to June 30, 1990, University of Utah, 1990.

3. F.A. Cotton and L. Wilkinson, Advanced Inorganic Chemistry, 3rd Edition (1972), Interscience Publishers, John Wiley and Sons, pp.431-434; 452-453. 


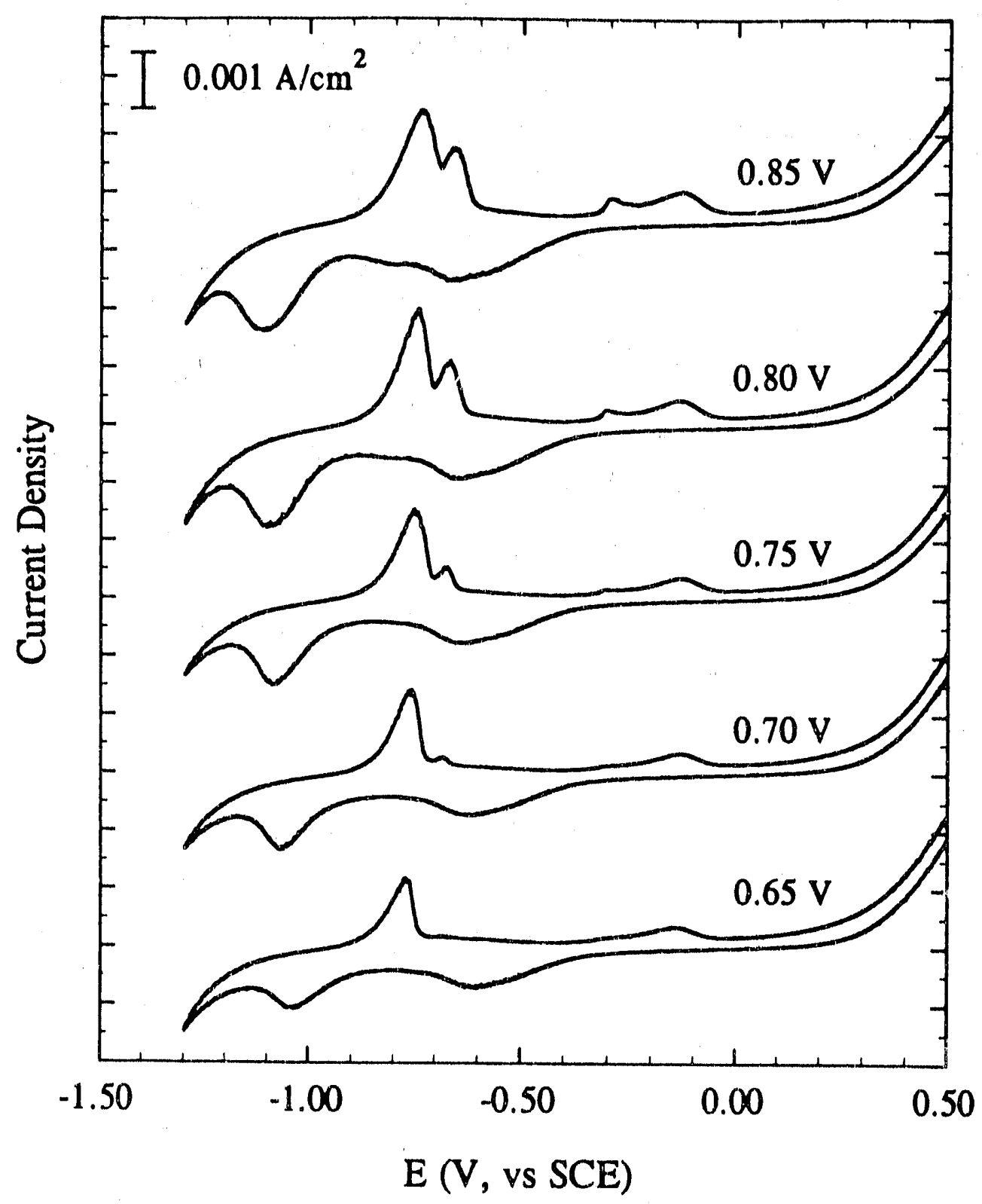

Figure 1. Mineral Pyrite in Borate Solutions at pH 9.2. Scan Reversed at Various Anodic Limits, Scan Rate, $50 \mathrm{mV} / \mathrm{s}$. RDE r.p.m. $=200$ 


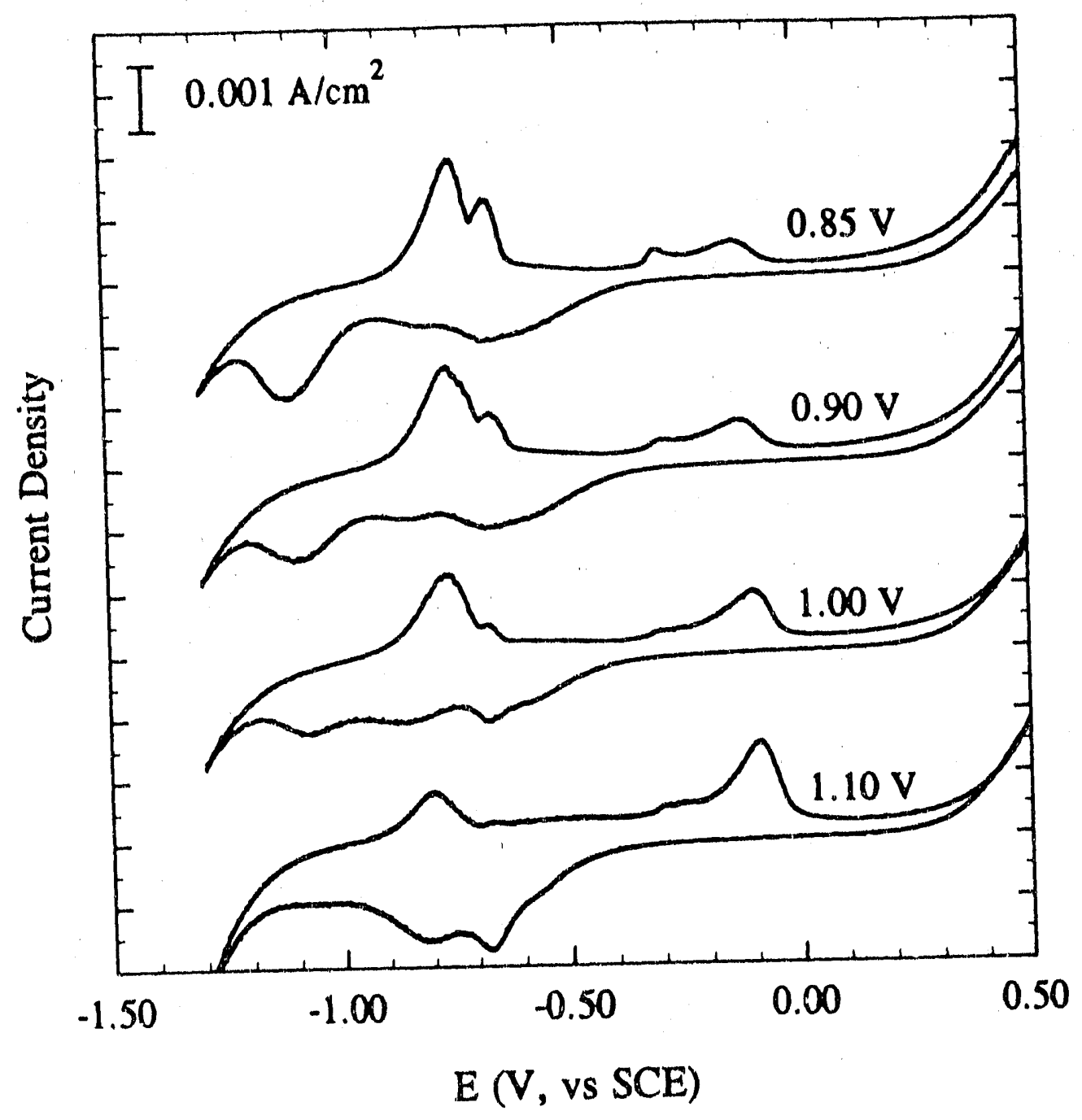

Figure 2. Mineral Pyrite in Borate Solutions at $\mathrm{pH} 9.2$. Scan Reversed at
Various Anodic Limits, Scan Rate, $50 \mathrm{mV} / \mathrm{s}$. RDE r.p.m. $=200$ 


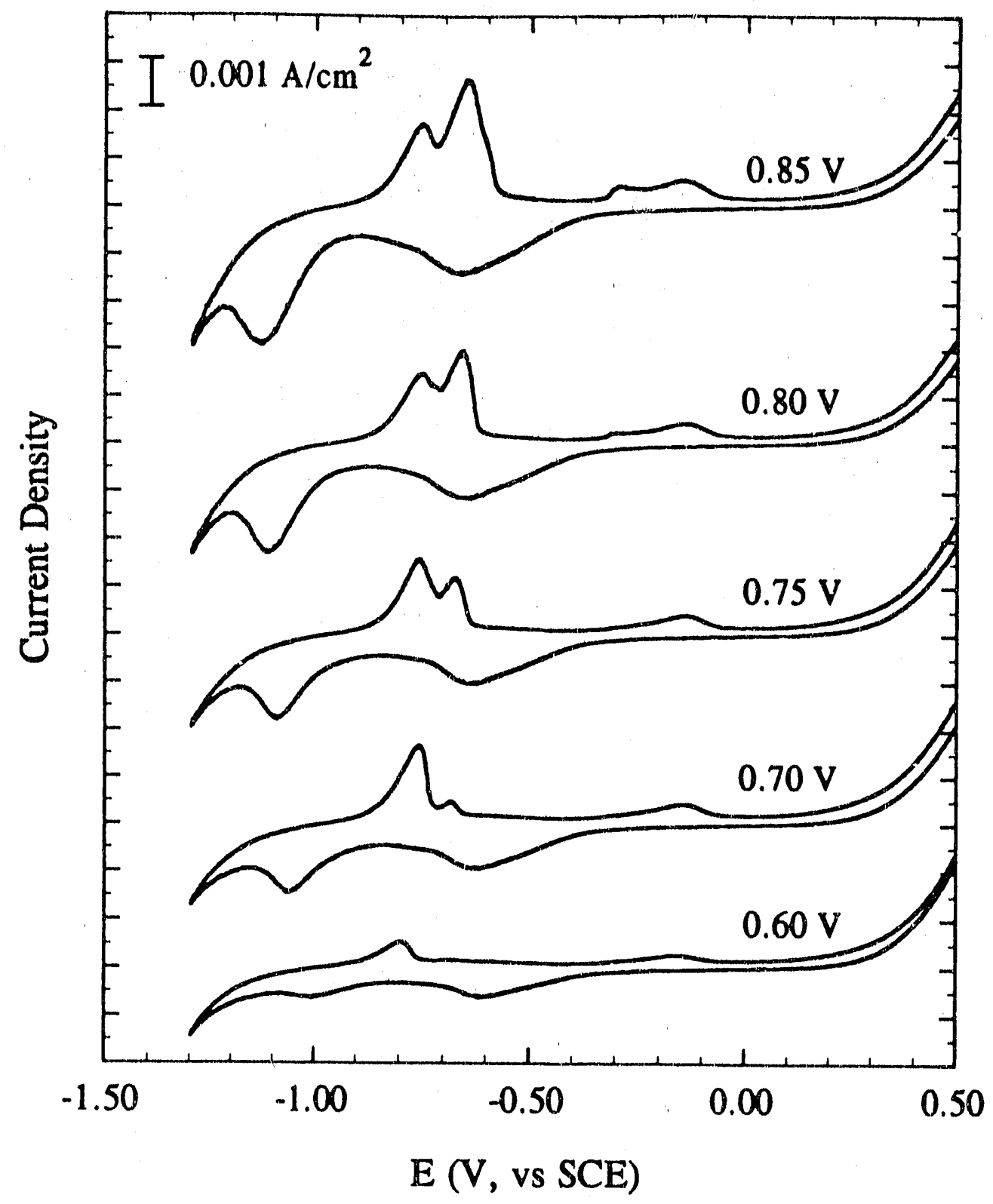

Figure 3. Mineral Pyrite in Borate Solutions at pH 9.2. Scan Reversed at Various Anodic Limits, Scan Rate, $50 \mathrm{mV} / \mathrm{s}$. RDE r.p.m. $=700$ 


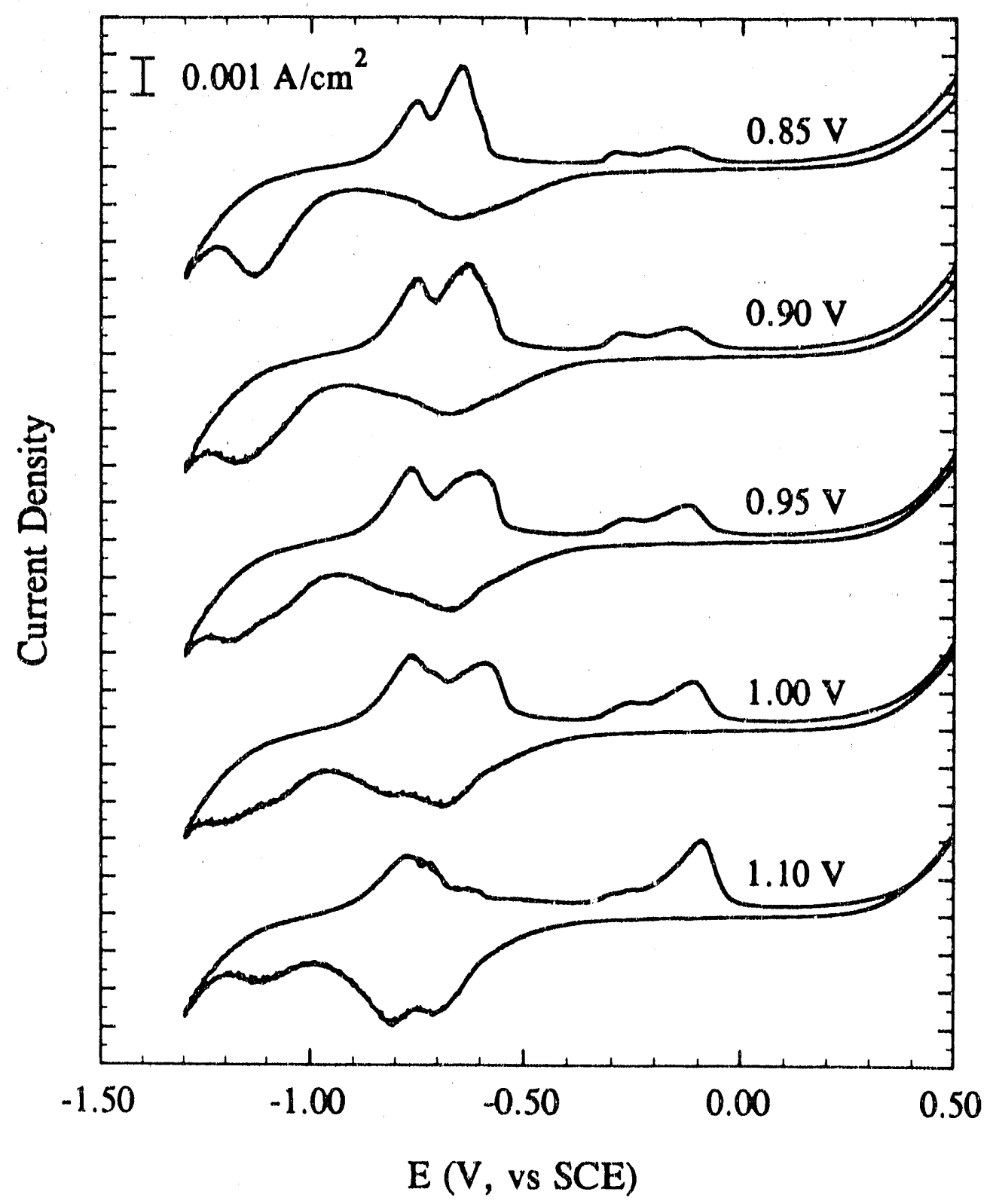

Figure 4. Mineral Pyrite in Borate Solutions at pH 9.2. Scan Reversed at Various Anodic Limits, Scan Rate, $50 \mathrm{mV} / \mathrm{s}$. RDE r.p.m. $=700$ 


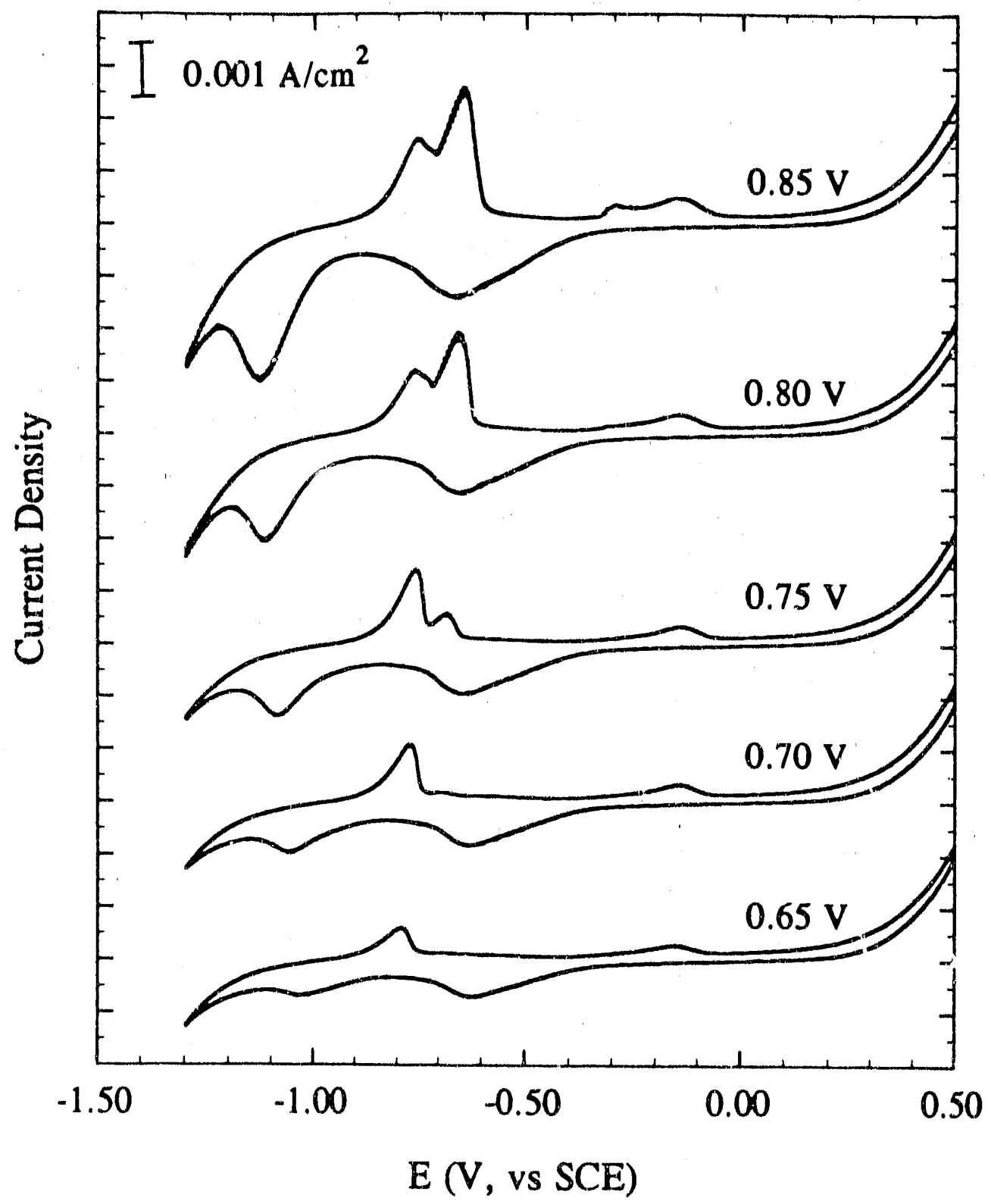

Figure 5. Mineral Pyrite in Borate Solutions at pH 9.2. Scan Reversed at Various Anodic Limits, Scan Rate, $50 \mathrm{mV} / \mathrm{s}$. RDE r.p.m. $=1000$ 


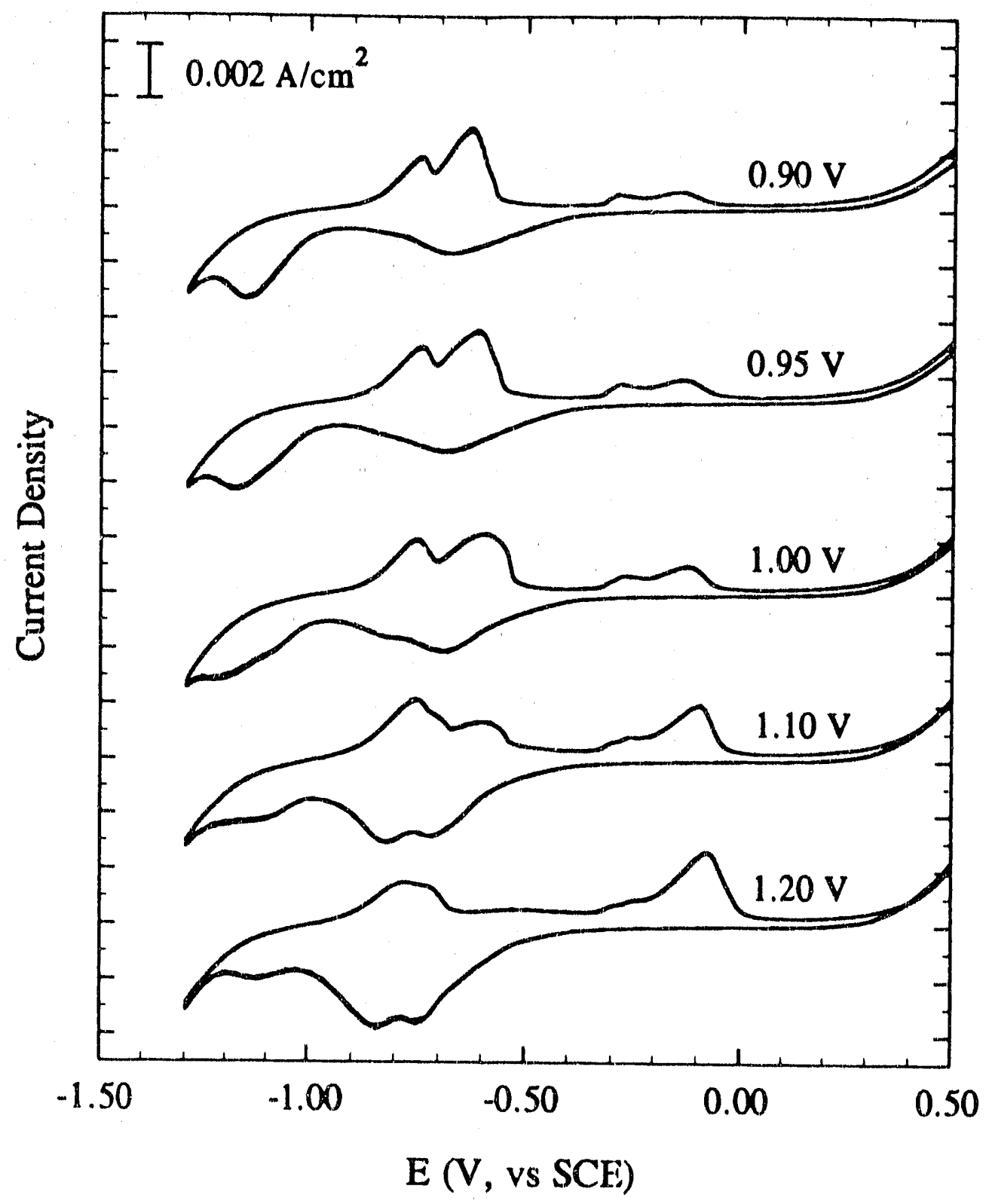

Figure 6. Mineral Pyrite in Rorate Solutions at pH 9.2. Scan Reversed at Various Anodic Limits, Scan Rate, $50 \mathrm{mV} / \mathrm{s}$. RDE r.p.m. $=1000$ 


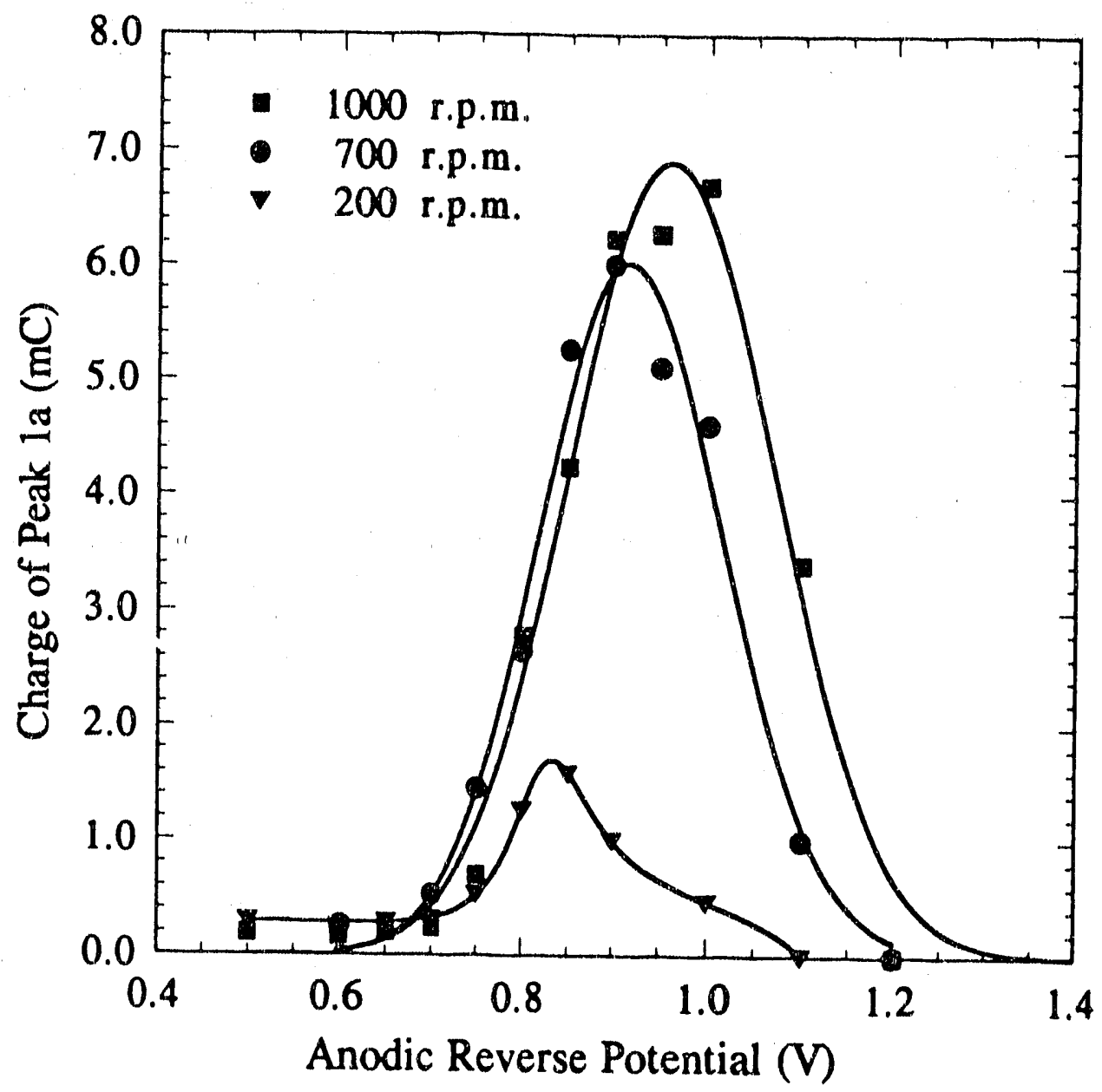

Figure 7. Mineral Pyrite in Borate Solutions at pH 9.2 for Various Anodic Limits. Scan Rate : $50 \mathrm{mV} / \mathrm{S}$. 


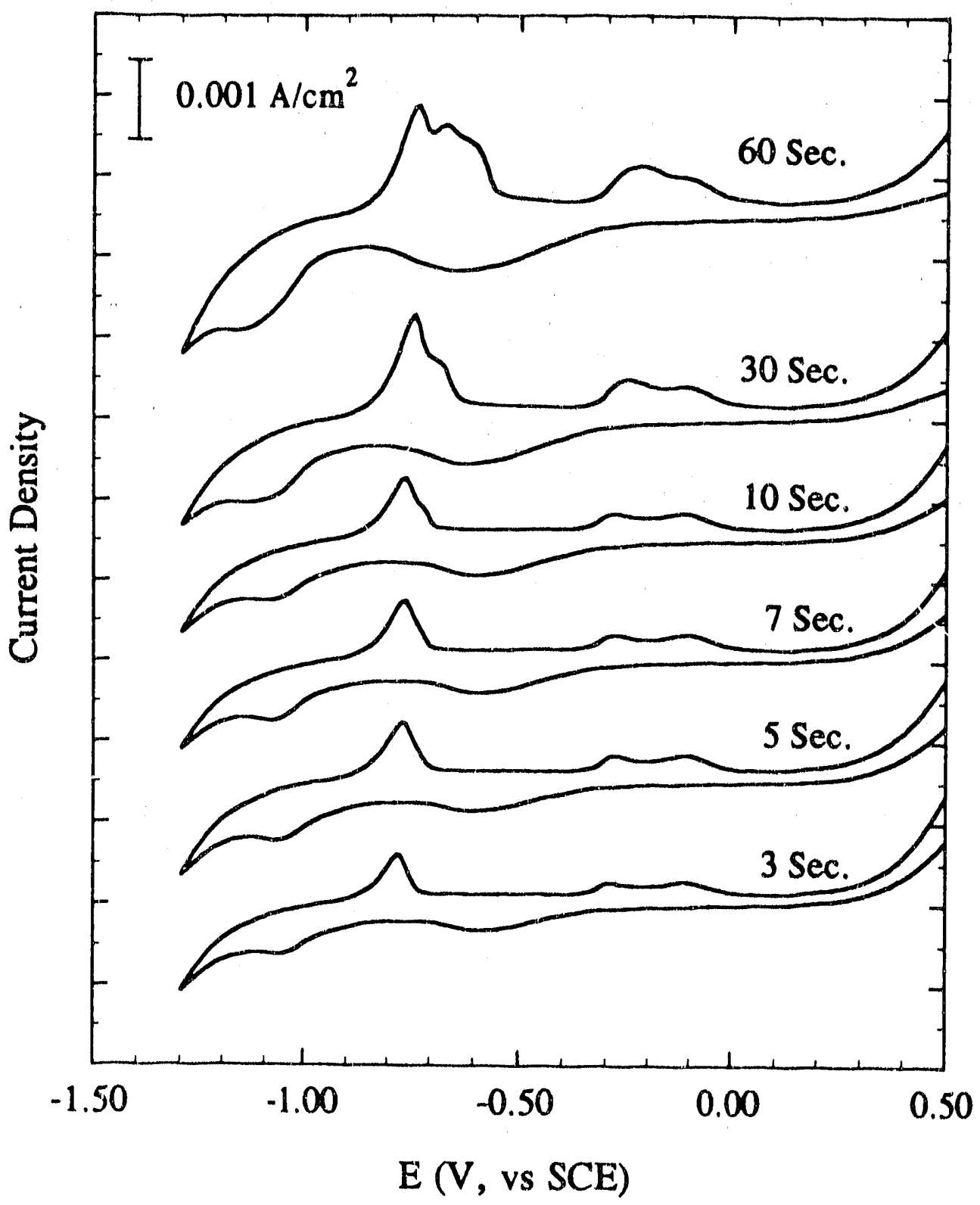

Figure 8. Mineral Pyrite in Borate Solutions at pH 9.2. Electrode Pre-conditioned at $0.6 \mathrm{~V}$ for Various Times. Scan Rate, $50 \mathrm{mV} / \mathrm{s}$. RDE r.p.m. $=0$ 


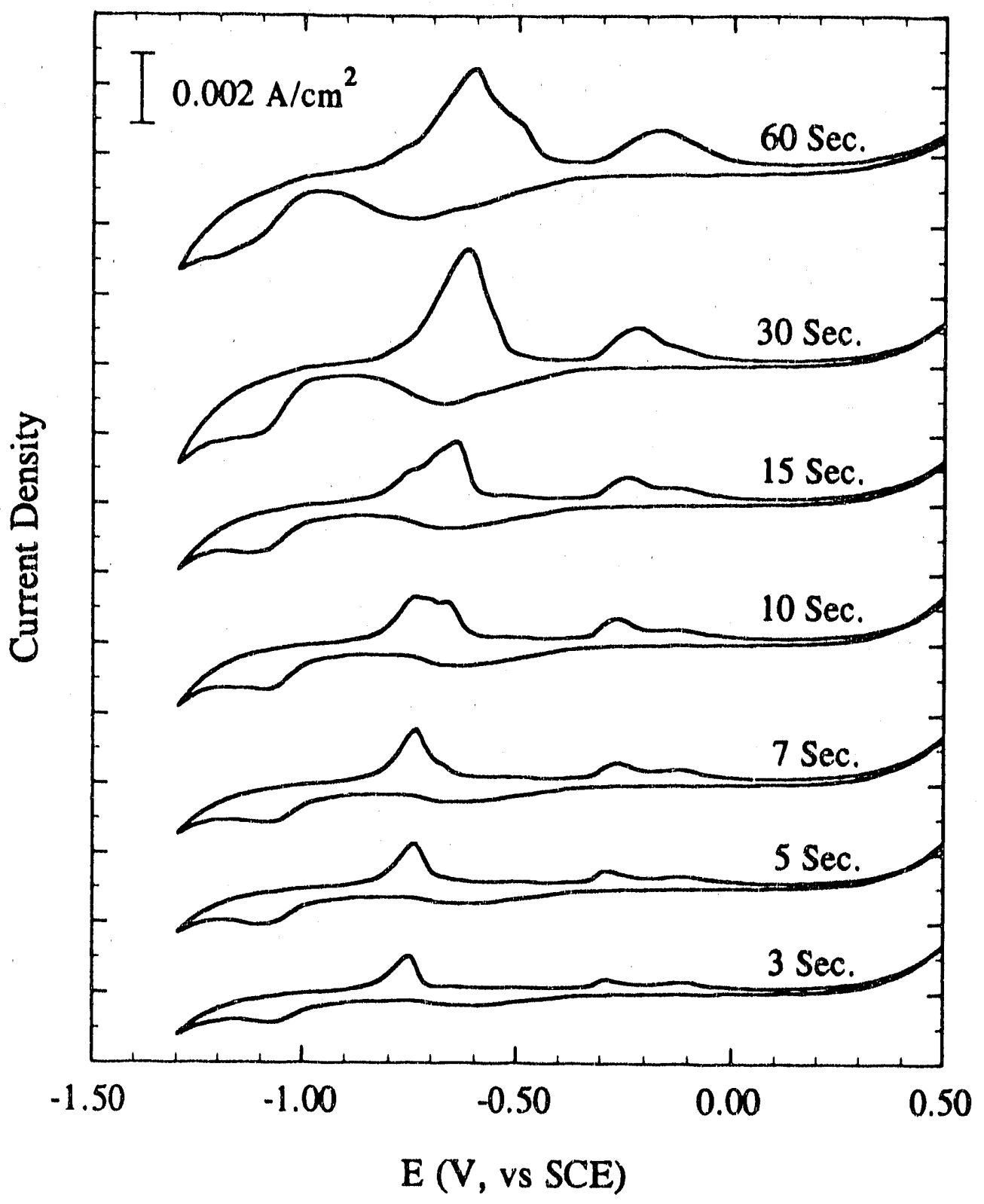

Figure 9. Mineral Pyrite in Borate Solutions at pH 9.2. Electrode Pre-conditioned at $0.6 \mathrm{~V}$ for Various Times. Scan Rate, $50 \mathrm{mV} / \mathrm{s}$. RDE r.p.m. $=200$ 


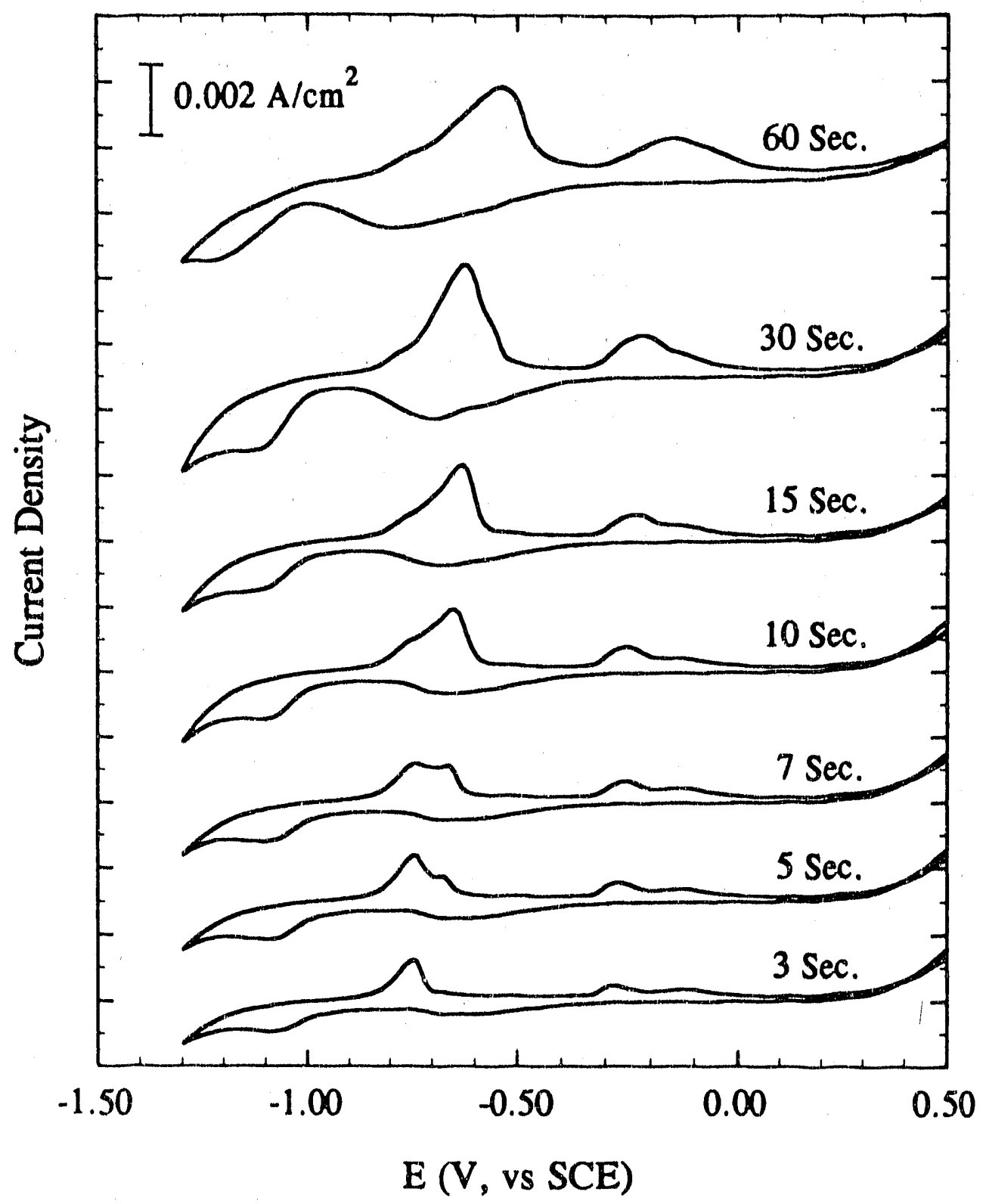

Figure 10. Mineral Pyrite in Borate Solutions at pH 9.2. Electrode Pre-conditioned at $0.6 \mathrm{~V}$ for Various Times. Scan Rate, $50 \mathrm{mV} / \mathrm{s}$. RDE r.p.m. $=1000$ 


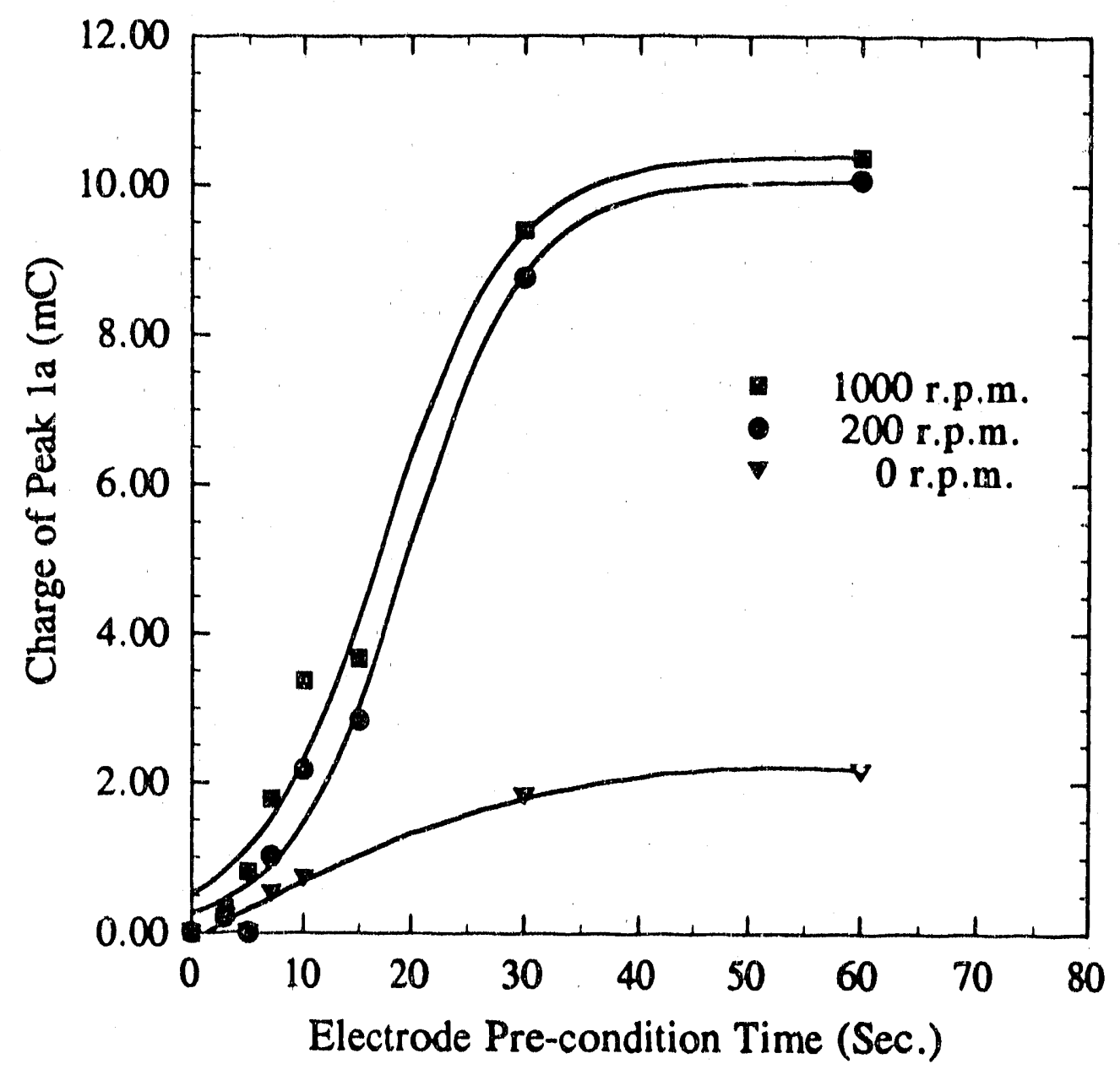

Figure 11. Mineral Pyrite in Borate Solutions at pH 9.2.

Electrode Pre-conditioned at $0.6 \mathrm{~V}$. Scan Rate : $50 \mathrm{mV} / \mathrm{s}$. 


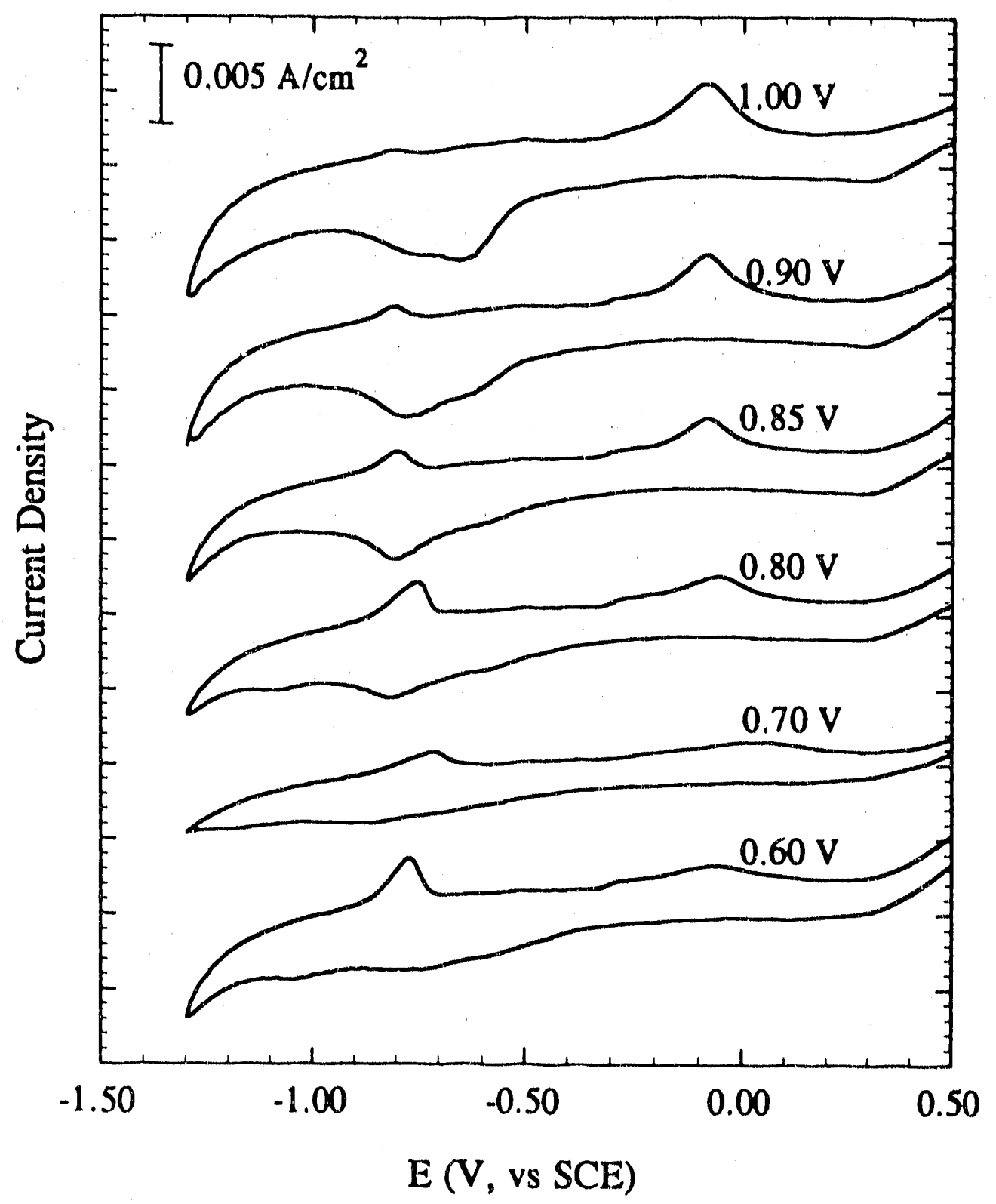

Figure 12. Illinois Coal Pyrite in Borate Solutions at pH 9.2. Scan Reversed at Various Anodic Limits, Scan Rate, $50 \mathrm{mV} / \mathrm{s}$. RDE r.p.m. $=200$ 


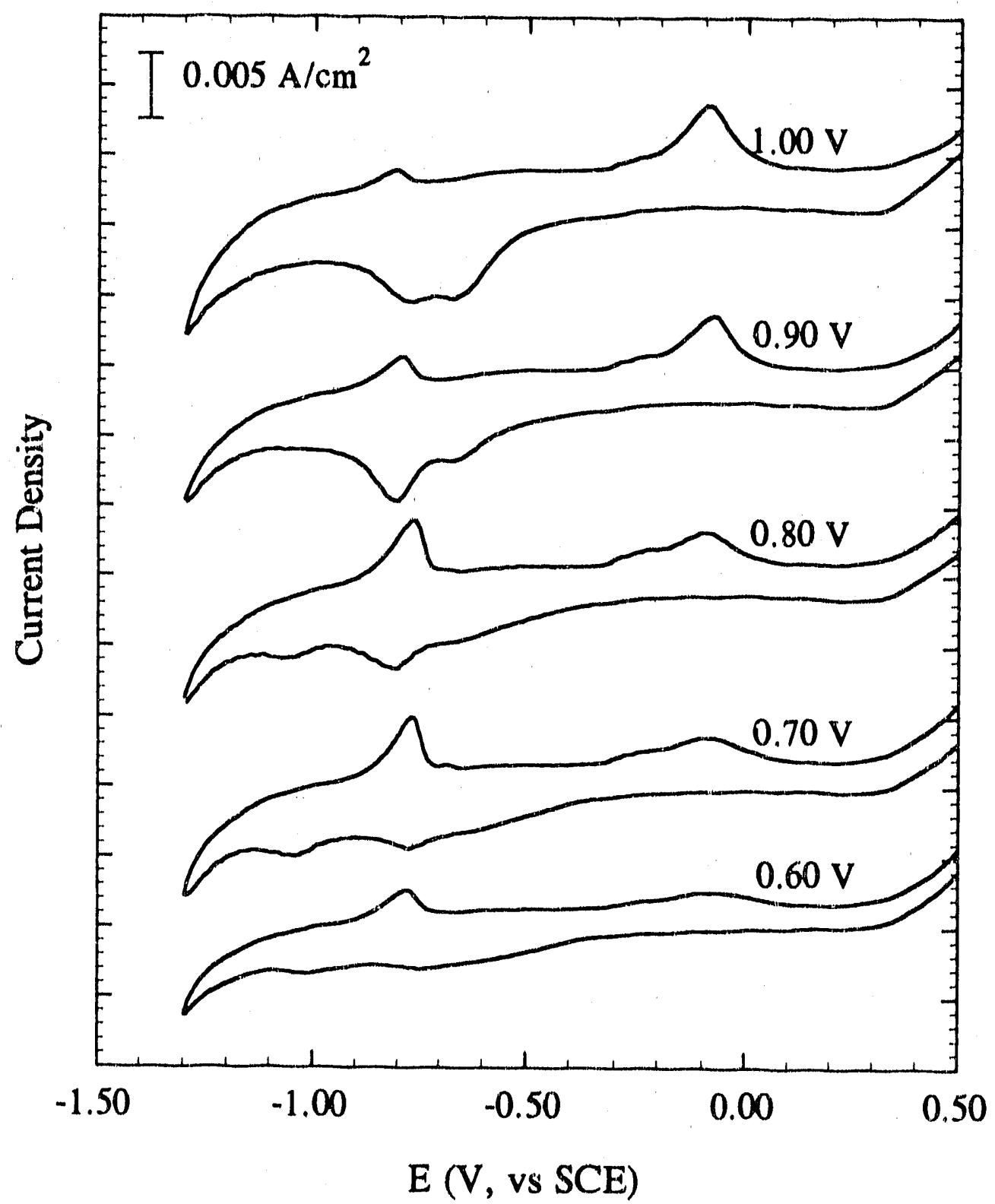

Figure 13. Illinois Coal Pyrite in Borate Solutions at pH 9.2. Scan Reversed at Various Anodic Limits, Scan Rate, $50 \mathrm{mV} / \mathrm{s}$. RDE r.p.m. $=700$ 


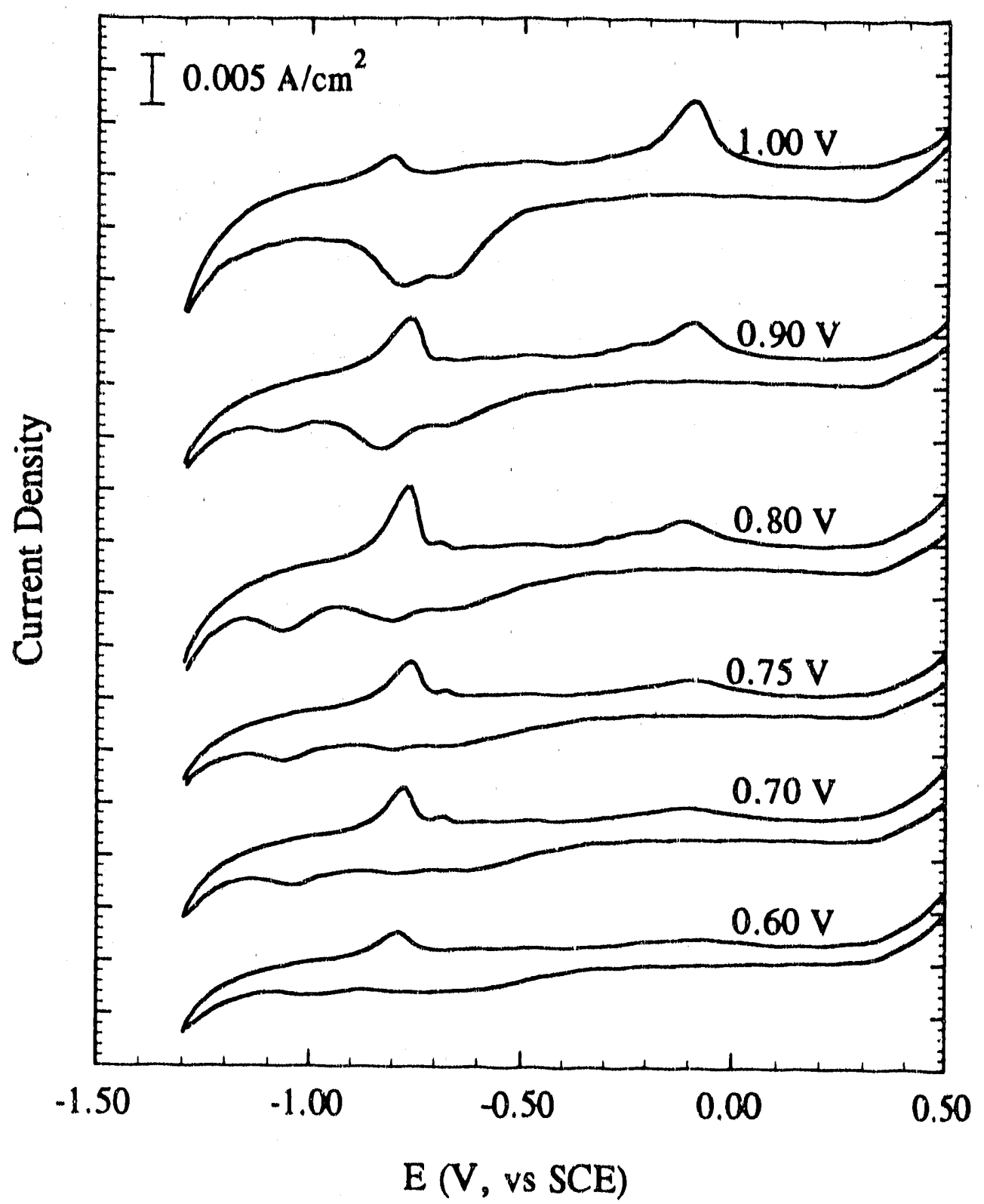

Figure 14. Illinois Coal Pyrite in Borate Solutions at pH 9.2. Scan Reversed at Various Anodic Limits, Scan Rate, $50 \mathrm{mV} / \mathrm{s}$. RDE r.p.m. $=2000$ 


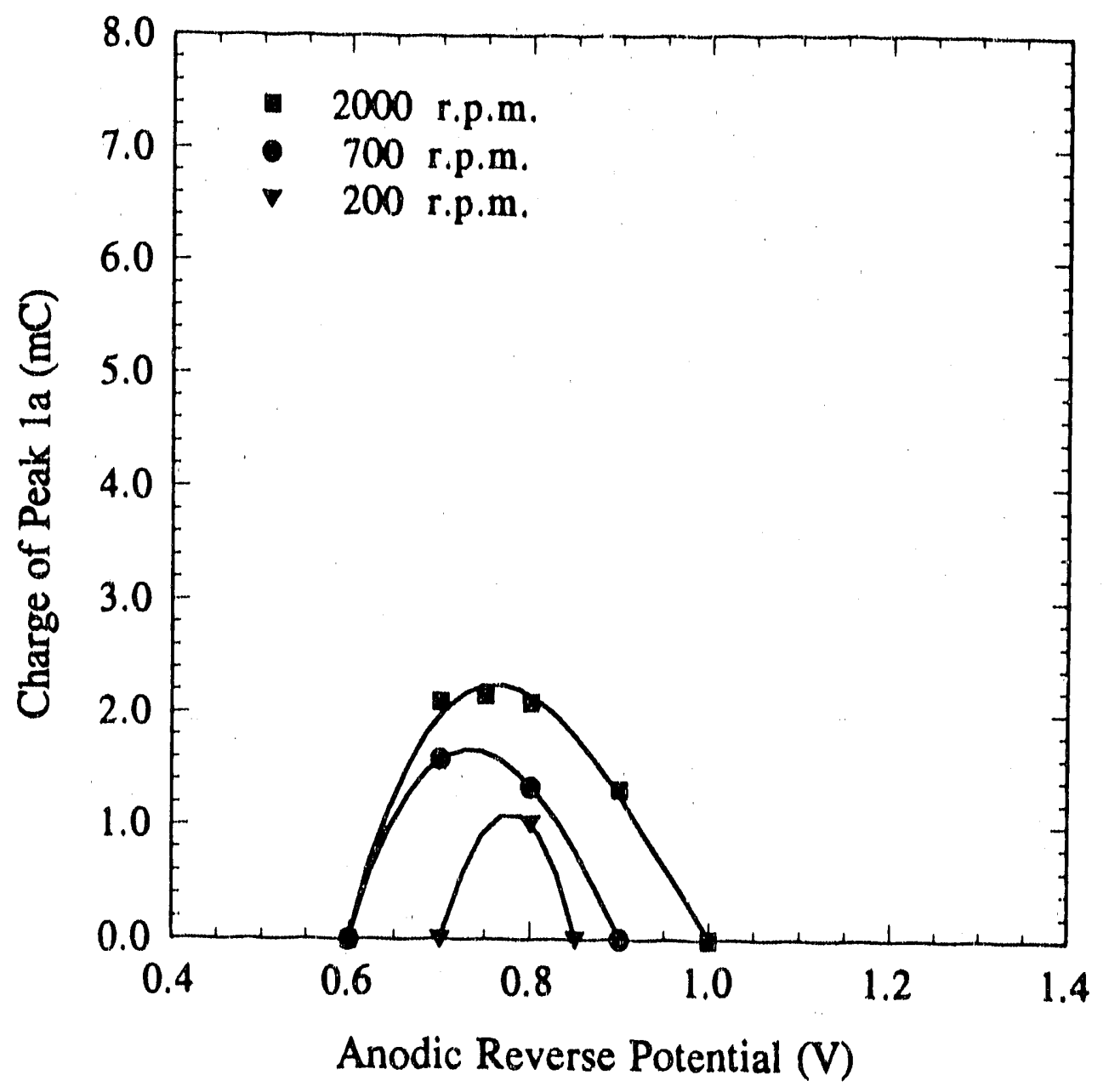

Figure 15. Illinois Coal Pyrite in Borate Solutions at pH 9.2 for Various Anodic Limits Scan Rate : $50 \mathrm{mV} / \mathrm{S}$. 


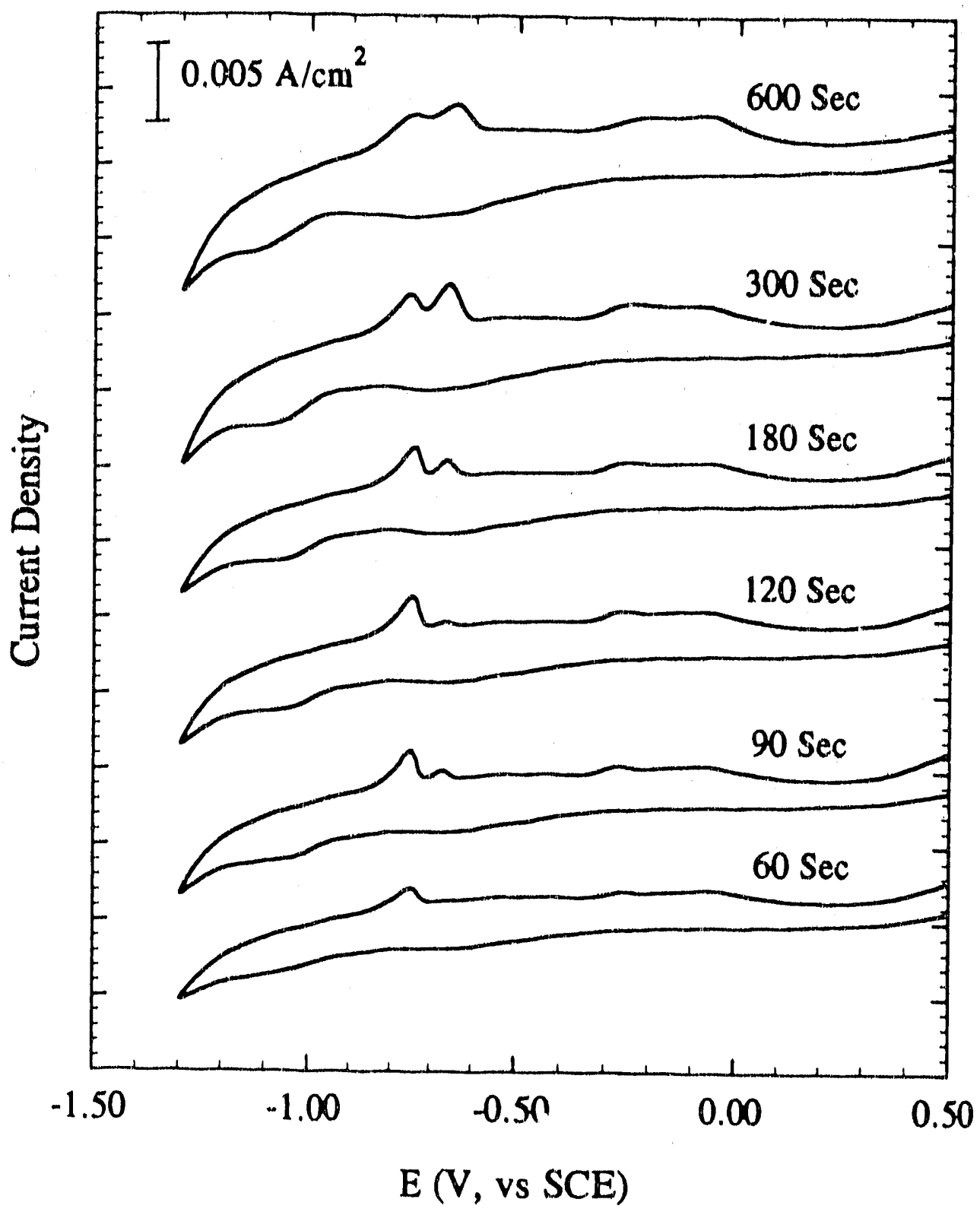

Figure 16. Illinois Coal Pyrite in Borate Solutions at pH 9.2. Electrode Pre-conditioned at $0.4 \mathrm{~V}$ for Various Times. Scan Rate, $50 \mathrm{mV} / \mathrm{s}$. RDE r.p.m. $=0$ 


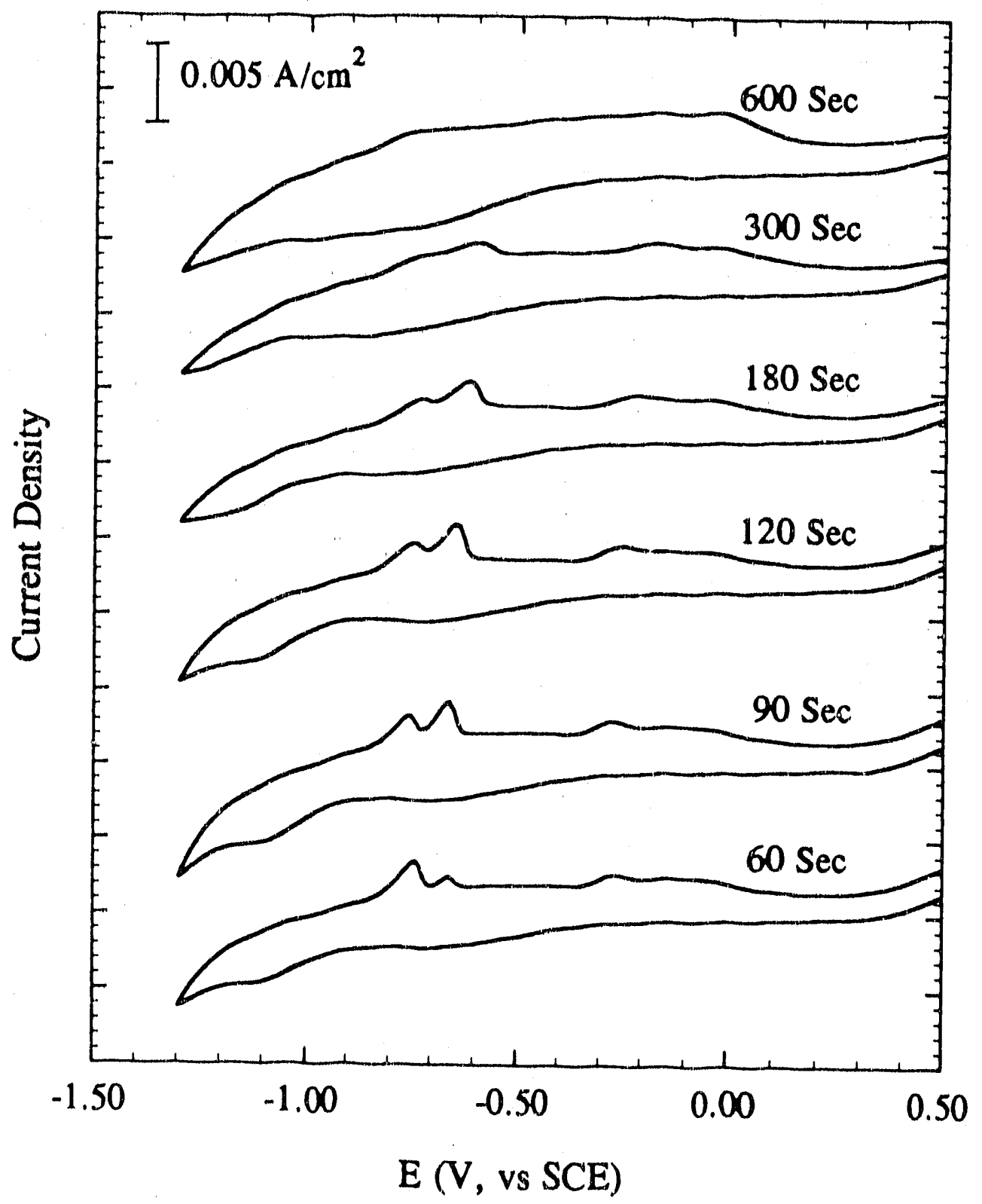

Figure 17. Illinois Coal Pyrite in Borate Solutions at pH 9.2. Electrode Pre-conditioned at $0.4 \mathrm{~V}$ for Various Times. Scan Rate, $50 \mathrm{mV} / \mathrm{s}$. RDE r.p.m. $=200$ 


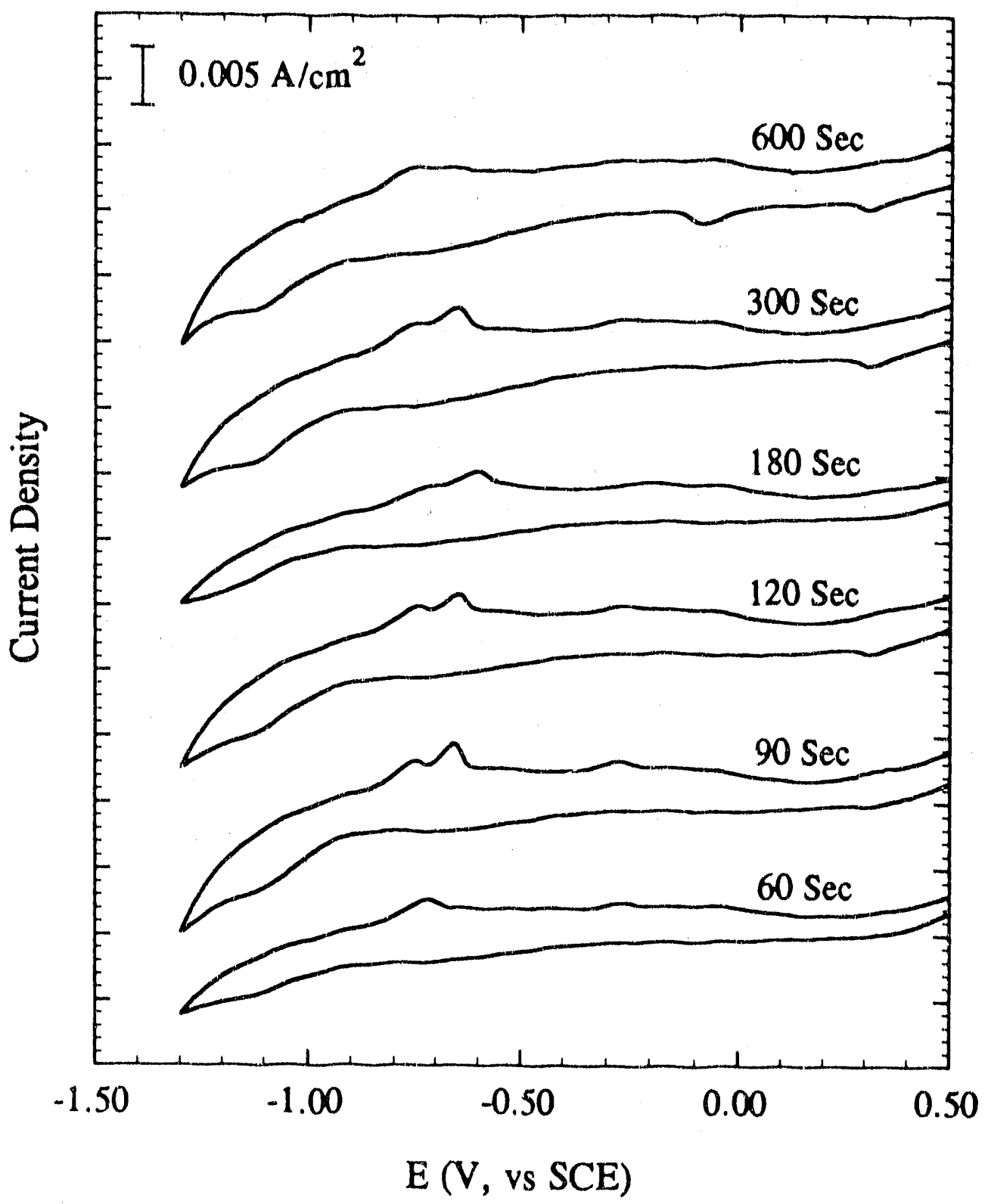

Figure 18. Illinois Coal Pyrite in Borate Solutions at pH 9.2. Electrode Pre-conditioned at $0.4 \mathrm{~V}$ for Various Times. Scan Rate, $50 \mathrm{mV} / \mathrm{s}$. RDE r.p.m. $=1000$ 


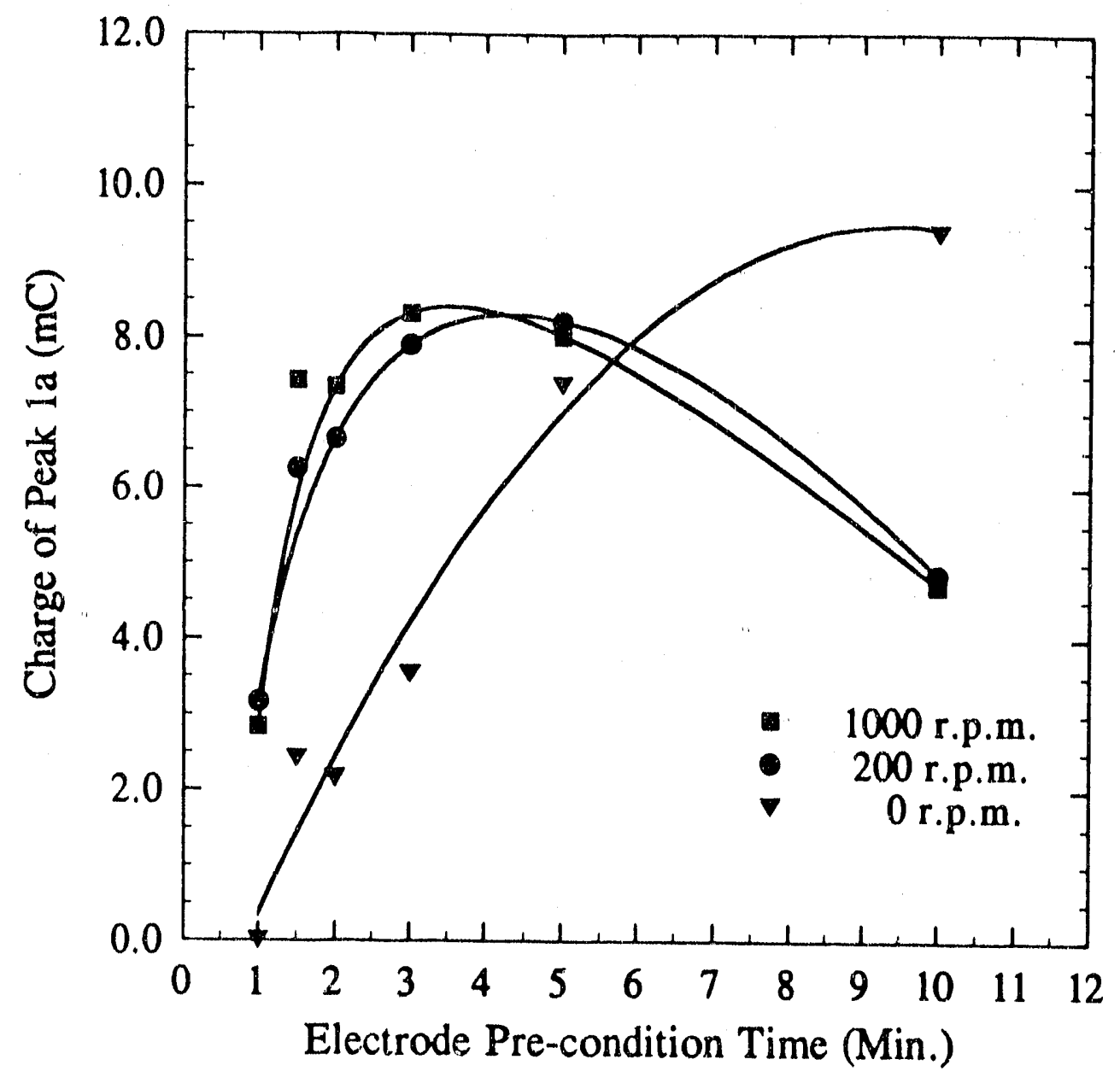

Figure 19. Illinois Coal Pyrite in Borate Solutions at pH 9.2. Electrode Pre-conditioned at $0.4 \mathrm{~V}$. Scan Rate : $50 \mathrm{mV} / \mathrm{s}$. 


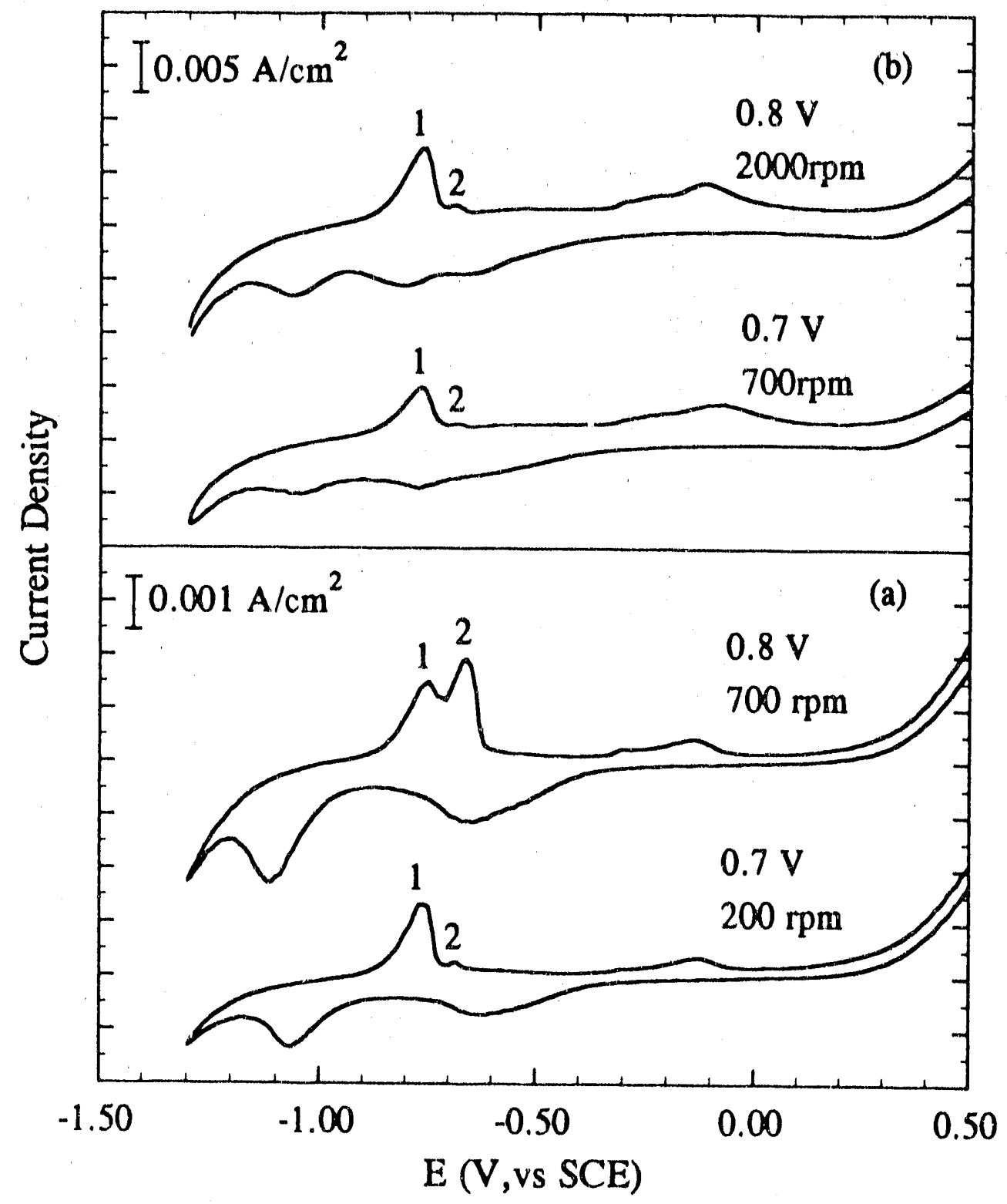

Figure 20. Effect of electrode rotation speed and anodic scan reversal potential on the magnitude of ferrous hydroxide peak (1) and iron sulfide peak (2) for mineral pyrite (a) and Illinois coal pyrite (b). 


\section{FLOTATION AND ELECTROCHEMICAL PRETREATMENT}

\section{INTRODUCTION}

In the past quarter, research on flotation and electrochemical pretreatment was extended in three areas: (1) floatability of mineral pyrite, coal pyrite and coal in xanthateelectrolyte solution; (2) the effect of electrochemical pretreatment on floatability of coal pyrite; and (3) the influence of lime addition on floatability of coal pyrite.

\section{RESULTS AND DISCUSSION}

\section{Floatability of Mineral Pyrite, Pittsburgh Coal Pyrite and Coal in Xauthate-}

\section{Electrolyte Solution}

In a previous report (1), it was illustrated that mineral and coal pyrite floated very well in acid xanthate solution, but were depressed in alkaline xanthate solution. In both cases, there is low floatability at $\mathrm{pH}$ values around 4 , which is close to the natural $\mathrm{pH}$ of the pulps. Figure 1 shows the floatability of mineral and Pittsburgh coal pyrite as a function of $\mathrm{pH}$ in xanthate solution with and without $\mathrm{Na}_{2} \mathrm{SO}_{4}$ and $\mathrm{Na}_{2} \mathrm{~B}_{4} \mathrm{O}_{7}$ electrolyte. The flotation behavior of mineral and coal pyrite is enhanced by the presence of electrolyte. The addition of sodium sulfate and sodium borate activated both mineral and coal pyrites and the depressed floatability around their natural $\mathrm{pH}$ disappeared. It may be concluded that sodium sulfate and sodium borate are effective activators for mineral and coal pyrite in xanthate solution in the $\mathrm{pH}$ range of this study.

Figure 2 illustrates the floatability of Pittsburgh coal and coal pyrite in xanthate 
electrolyte solution. It is clear that the floatability of coal is much higher than that of coal pyrite. For example, the floatabilities of coal and coal pyrite in solution with $1.68 \times 10^{-5} \mathrm{M}$ xanthate, $0.125 \mathrm{M} \mathrm{Na}_{2} \mathrm{SO}_{4}$, and $0.005 \mathrm{M} \mathrm{Na}_{2} \mathrm{~B}_{4} \mathrm{O}_{7}$ are $82.3 \%$ and $12.1 \%$ respectively.

\section{Effect of Electrochemical Pretreatment on the Floatability of Pittsburgh Coal Pyrite}

In our cyclic voltammetry and surface Raman spectroscopy study of mineral and coal pyrite, it was observed that hydrophobic sulfur or hydrophilic iron hydroxides can be formed under certain electrochemical conditions. The formation of sulfur enhances the floatability of the minerals, while the formation of metal hydroxide depresses the floatability of minerals. Figure 3 illustrates the effect of electrochemical pretreatment on the floatability of Pittsburgh coal pyrite at pH 7.0.

Sodium sulfate and sodium borate were added to the solution as supporting electrolyte. The coal pyrite electrochemically pretreated at a potential $+0.8 \mathrm{~V}$ displays much higher floatability due to the formation of elemental sulfur. Iron hydroxides may be produced at a potential of $-1.5 \mathrm{~V}$ and the floatability of pyrite decreases. This conclusion is consistent with results of our cyclic voltammetry and Raman spectroscopy experiments.

\section{Effect of Lime Addition on Floatability of Coal Pyrite}

Calcium cyanide has been frequently used as a depressant for mineral sulfides in flotation processes. In this study, lime was used as a depressant for coal pyrite. Figures 4 and 5 plot the effect of lime addition on the floatability of coal pyrite and coal. Lime was employed to adjust the $\mathrm{pH}$ of solutions to certain values. The floatability of coal pyrite 
increases with the dosage of xanthate, but decreases with the dosage of lime (indicated by the increase in $\mathrm{pH}$ values). In comparison with coal pyrite in xanthate-electrolyte solution (Figure 3), coal pyrite is depressed significantly in lime-xanthate solutions. Differing from coal pyrite, the floatability of Pittsburgh coal is depressed very much when the $\mathrm{pH}$ of the lime solution is more than 10 . The coal maintains its higher floatability until the $\mathrm{pH}$ of lime solution reaches 10. This situation is shown in Figures 5 and 6 . The largest difference of floatability between coal and coal pyrite is about $80 \%$.

Figures 7-9 illustrate the effects of electrochemical pretreatment on the floatability of coal pyrite in xanthate-lime solution without any other electrolyte for various $\mathrm{pH}$ values. Comparing Figures 7 and 8 with Figure 3, it is apparent that the positive effect of electrochemical treatment in supporting electrolyte on the floatability of coal pyrite is depressed by the addition of lime. The highest floatability of coal pyrite pretreated at $+0.8 \mathrm{~V}$ in $\mathrm{Na}_{2} \mathrm{SO}_{4}$ and $\mathrm{Na}_{2} \mathrm{~B}_{4} \mathrm{O}_{7}$ solution with $3.3 \times 10^{-4} \mathrm{M}$ xanthate is $66.3 \%$. The floatabilities of coal pyrite pretreated at the same conditions, except that $\mathrm{Na}_{2} \mathrm{SO}_{4}$ and $\mathrm{Na}_{2} \mathrm{~B}_{4} \mathrm{O}_{7}$ were replaced by lime (to adjust the $\mathrm{pH}$ of solutions to 10.0 and 12.3 ) were $9.2 \%$ and $5.1 \%$ respectively. Figures $6-8$ further illustrate the increased floatability of coal with decreased $\mathrm{pH}$. Therefore, it is expected that efficient separation of pyrite from coal should be obtained at pH 9-10 with lime used to adjust the pH of the solutions. Figure 8 does not show the beneficial effect of electrochemical treatment on the floatability of coal pyrite due to the lack of supporting electrolyte and the resultant high solution resistance. The addition of supporting electrolyte will certainly activate coal pyrite making the separation more difficult. 


\section{CONCLUSIONS}

1. The floatability of mineral and Pittsburgh coal pyrite increase with the addition of $\mathrm{Na}_{2} \mathrm{SO}_{4}$ and $\mathrm{Na}_{2} \mathrm{~B}_{4} \mathrm{O}_{7}$ electrolyte, which may be an activator for both.

2. The floatability of Pittsburgh coal pyrite decreases in the presence of lime. Lime is an effective depressant for coal pyrite.

3. Electrochemical pretreatment alters the flotation behavior of coal pyrite. The formation of hydrophobic sulfur or hydrophilic oxides will enhance or depress its floatability.

\section{REFERENCES}

1. W. Hu, Q. Huang, Andrew Riley, X. Zhu, David M. Bodily, J. Liang, T. Zhong and Milton E. Wadsworth, Surface Electrochemical Control for Fine Coal and Pyrite Separation, Department of Energy Technical Progress Report, April 1, 1991 to June 30, 1991, University of Utah, 1991. 


\begin{tabular}{lccc}
\multicolumn{1}{c}{ Sample } & & \multicolumn{2}{c}{ Solution $(\mathrm{M})$} \\
& Xanthate & $\mathrm{Na}_{2} \mathrm{SO}_{4}$ & $\mathrm{Na}_{2} \mathrm{~B}_{4} \mathrm{O}_{7}$ \\
1. Mineral Pyrite & $0.66 \times 10^{5}$ & 0.00 & 0.00 \\
2. Mineral Pyrite & $\mathbf{0 . 6 6 \times 1 0 ^ { - 5 }}$ & $\mathbf{0 . 4 9}$ & $\mathbf{0 . 0 1}$ \\
3. Coal Pyrite & $1.32 \times 10^{-4}$ & 0.00 & 0.00 \\
4. Coal Pyrite & $1.32 \times 10^{-4}$ & 0.49 & 0.01
\end{tabular}

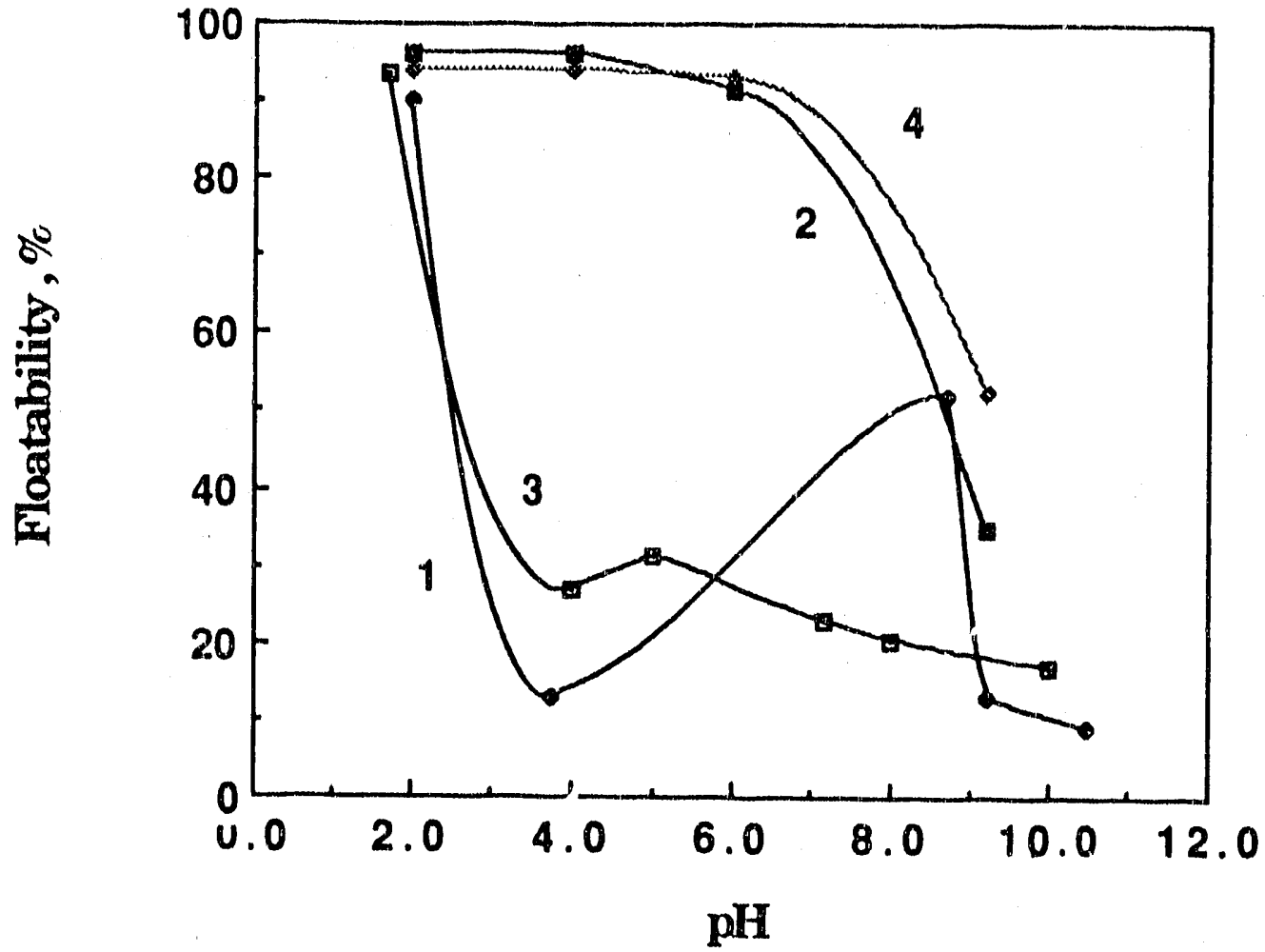

Figure 1 Floatability of Mineral and Coal

Pyrite as a Function of pH 


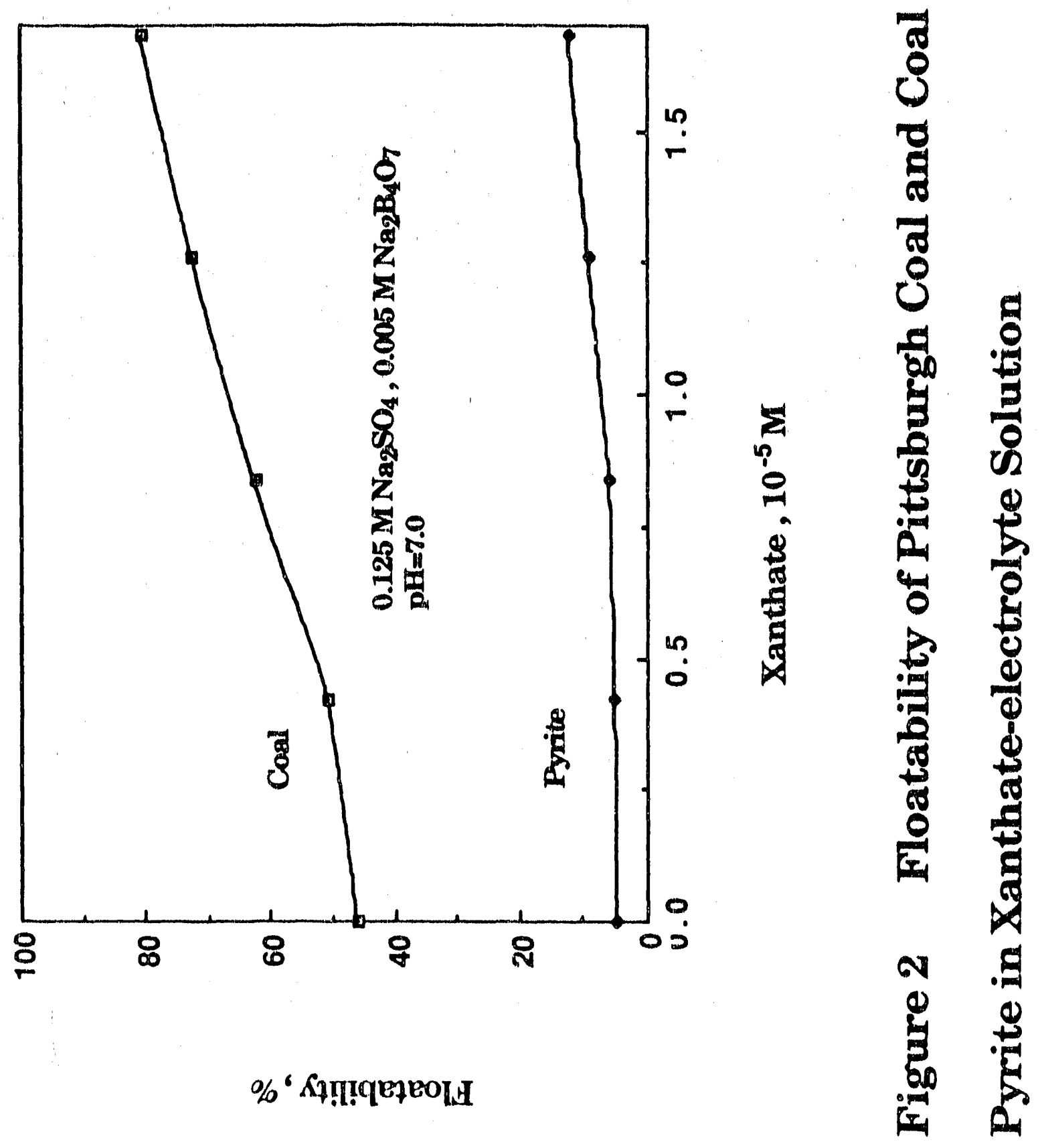




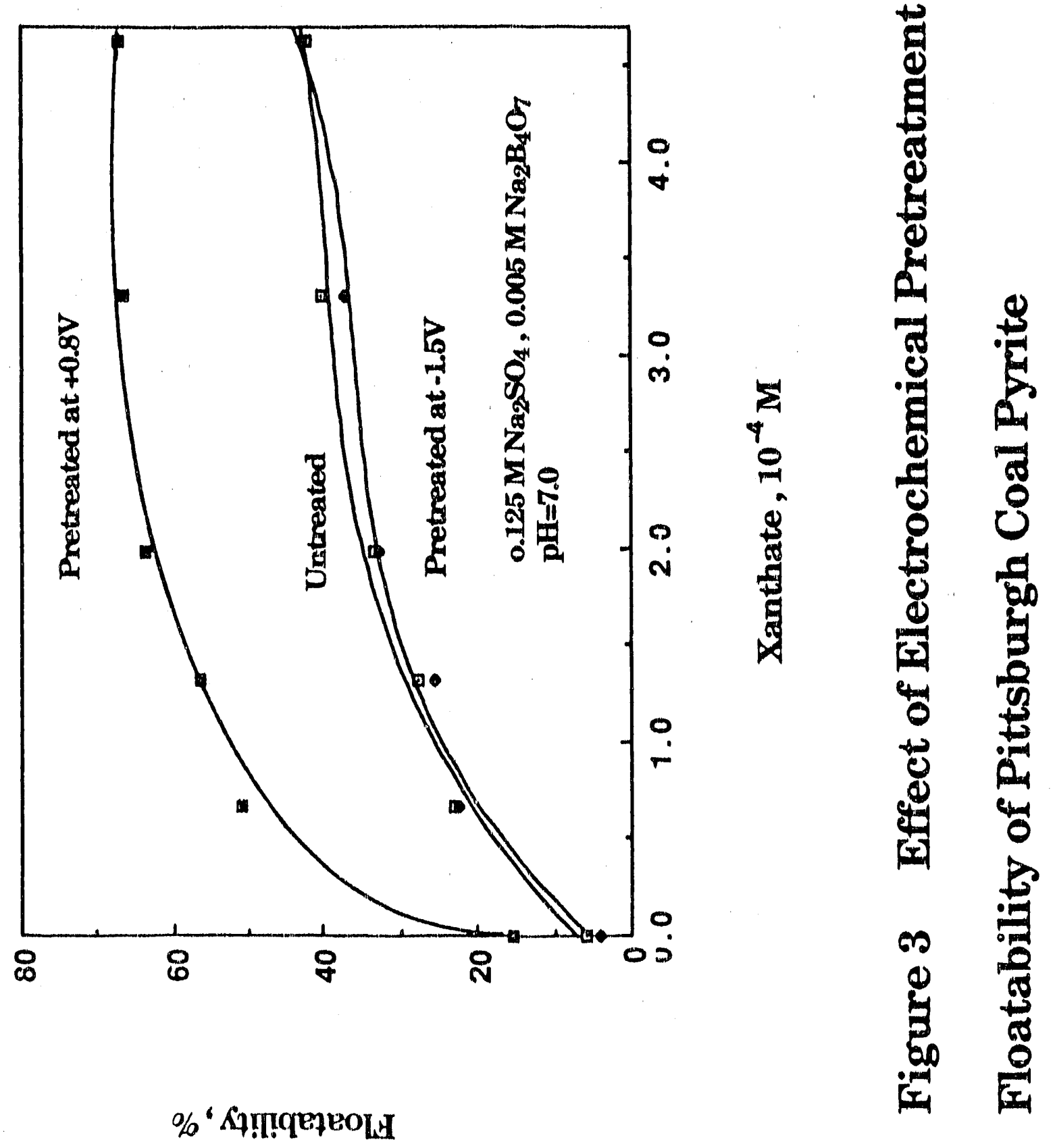




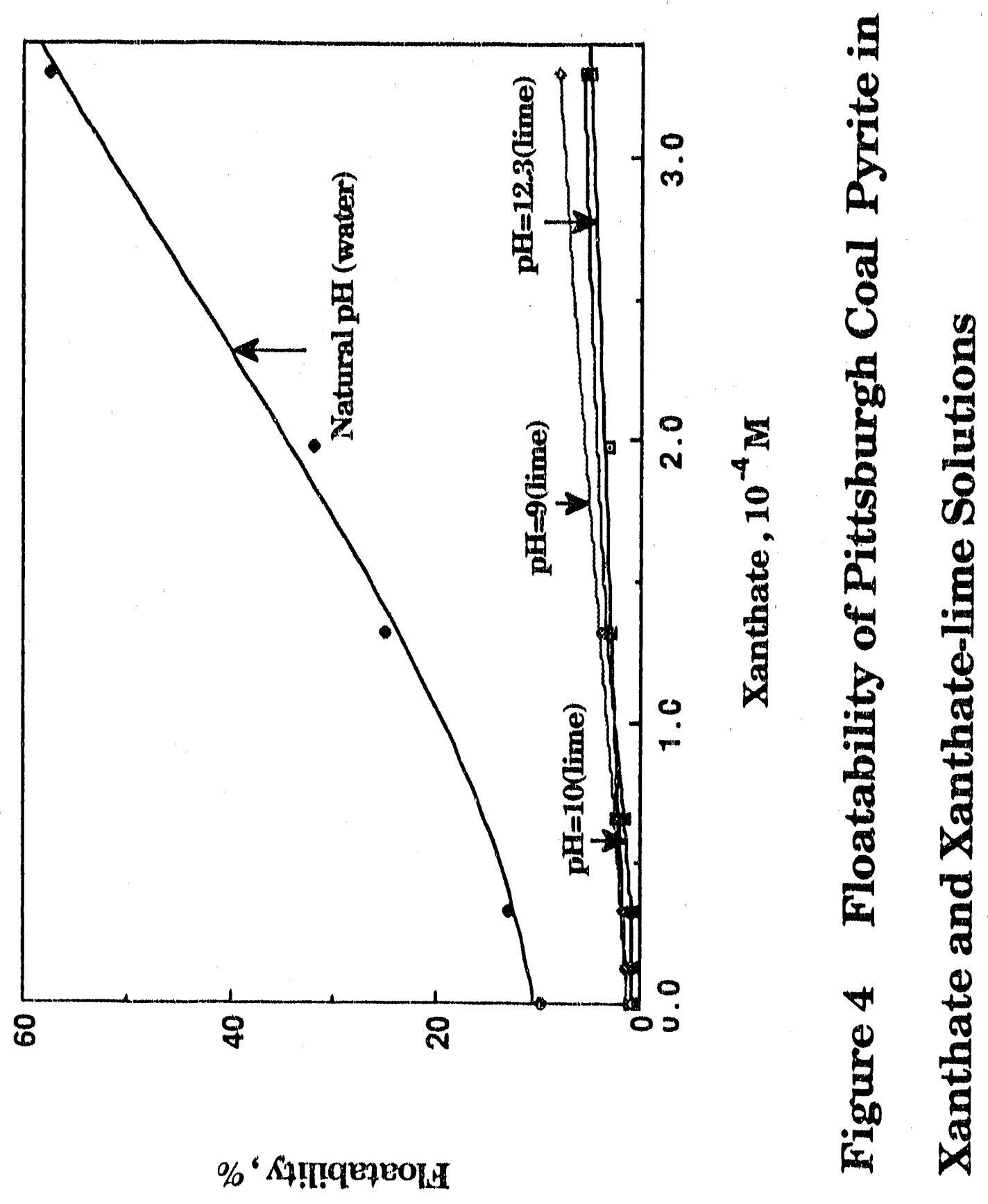



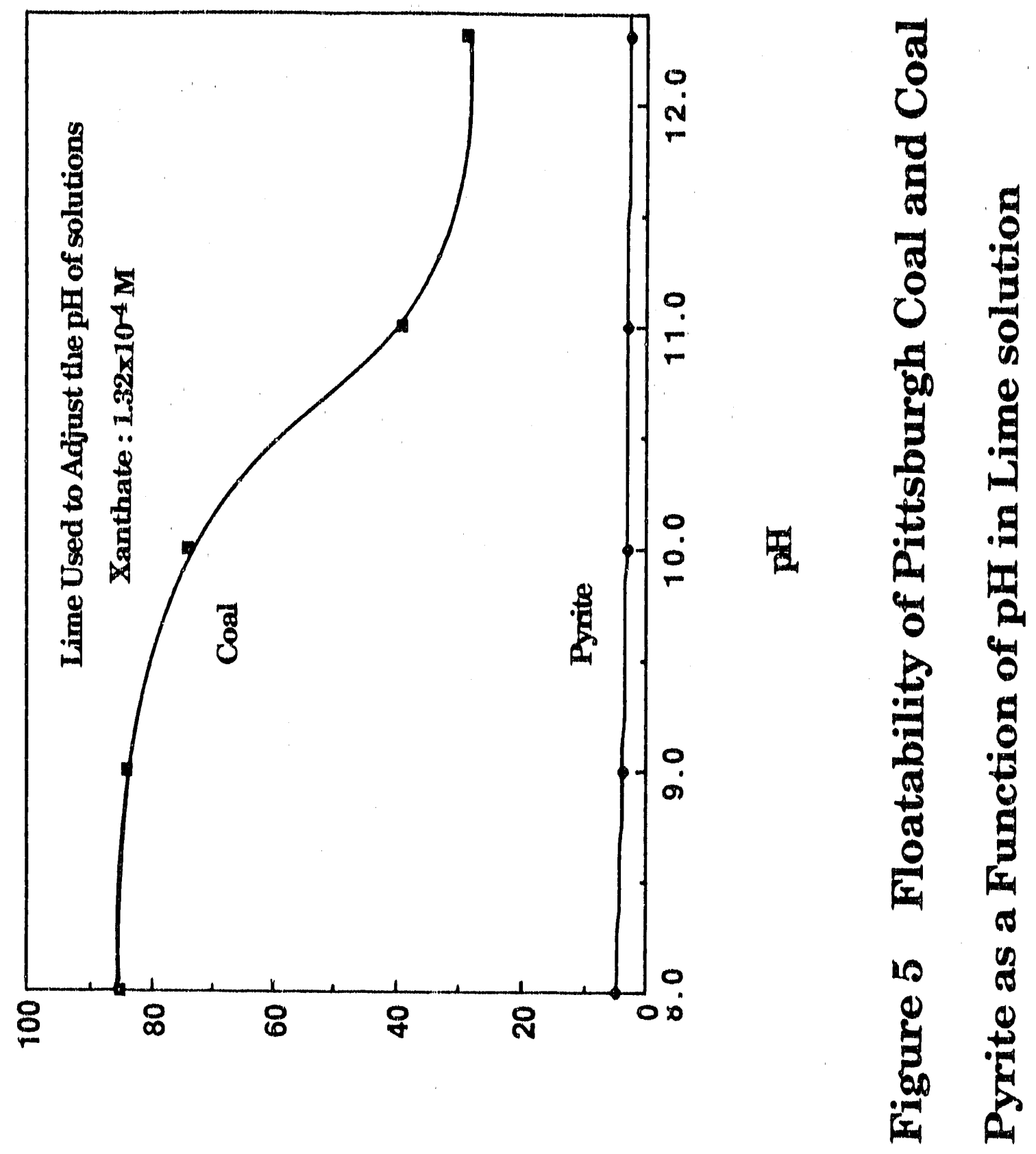

\%" SqIIIqEqEOLH 


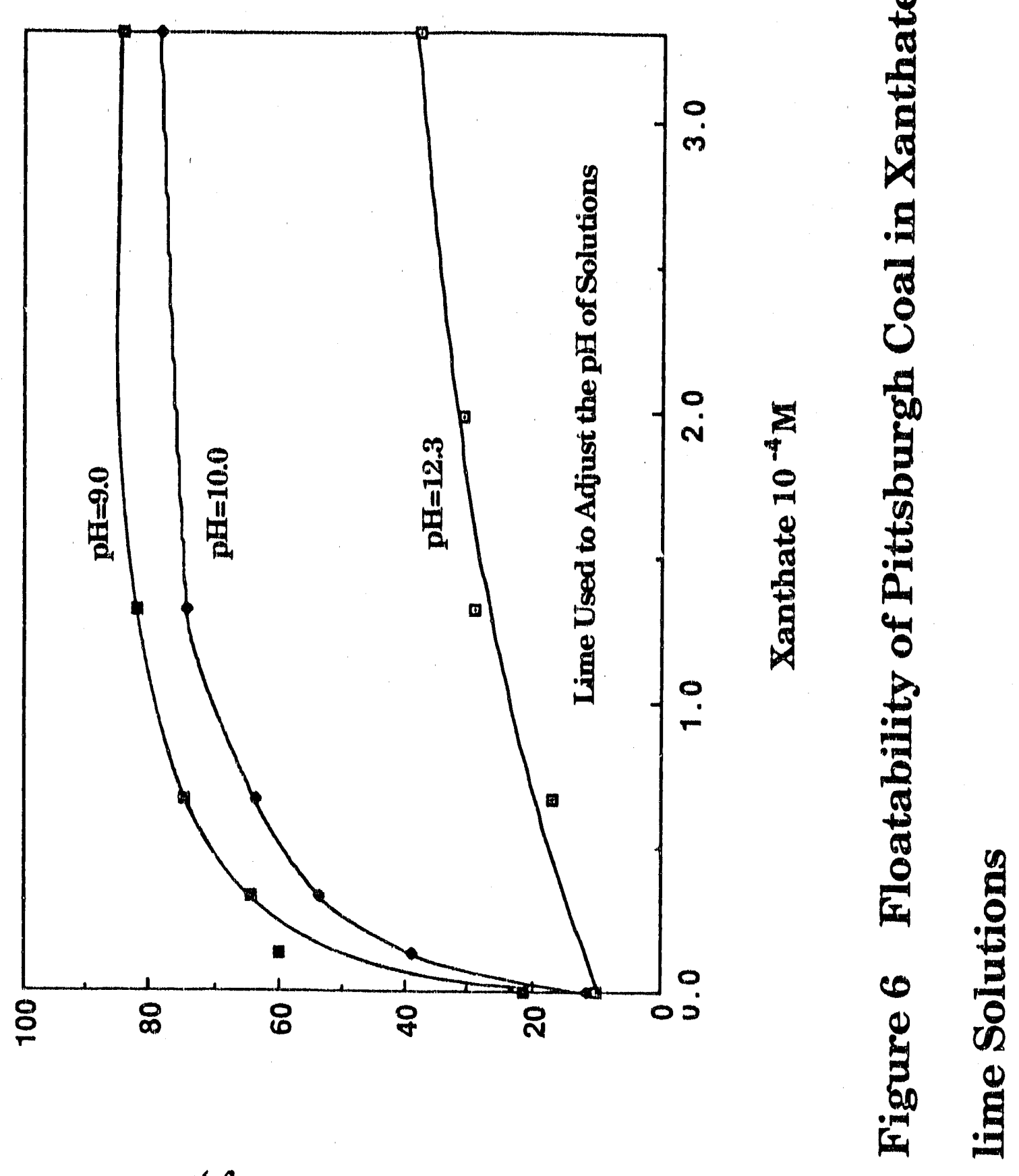

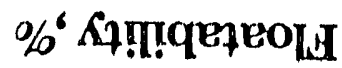



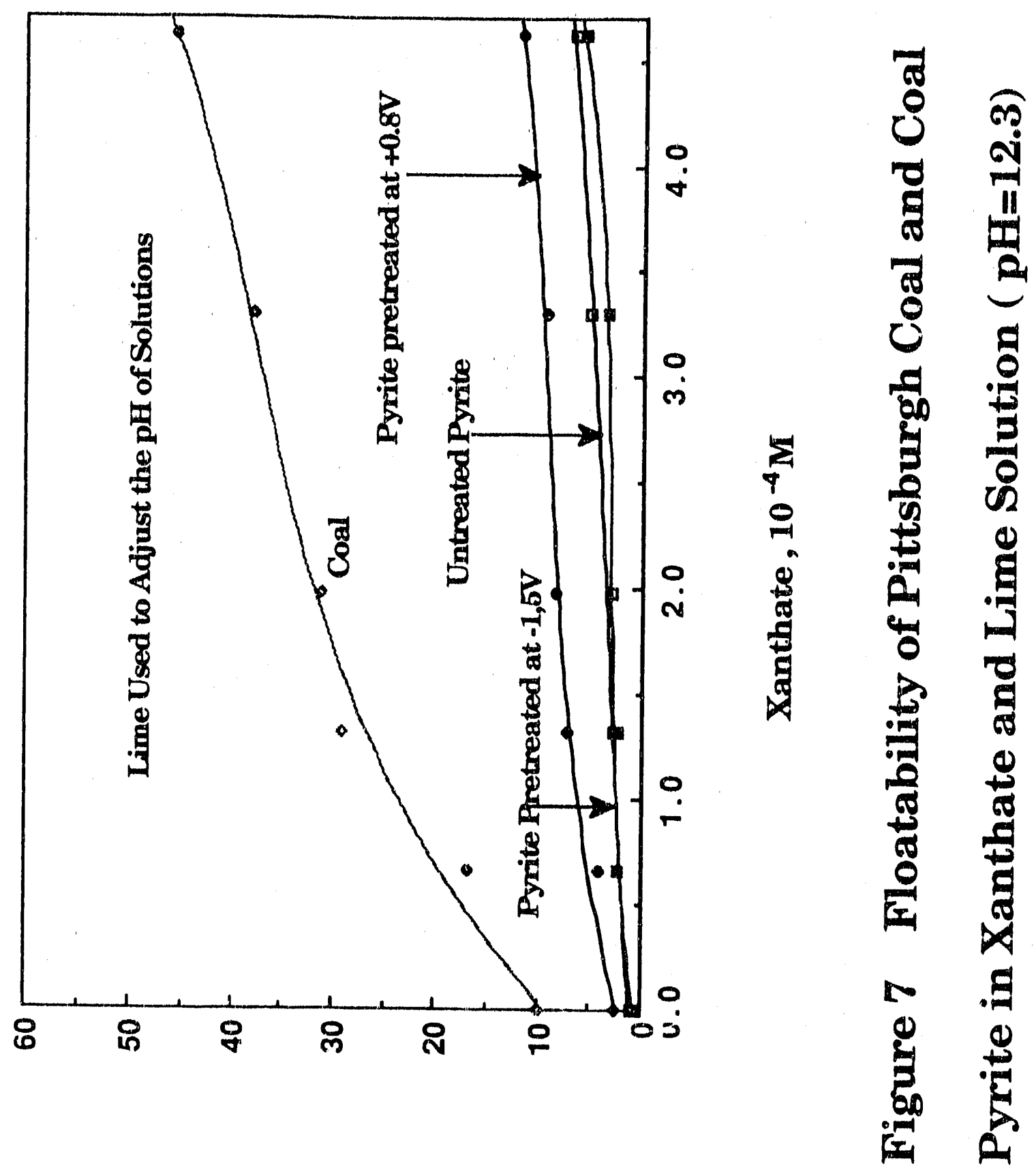

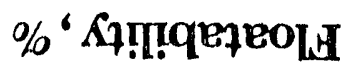




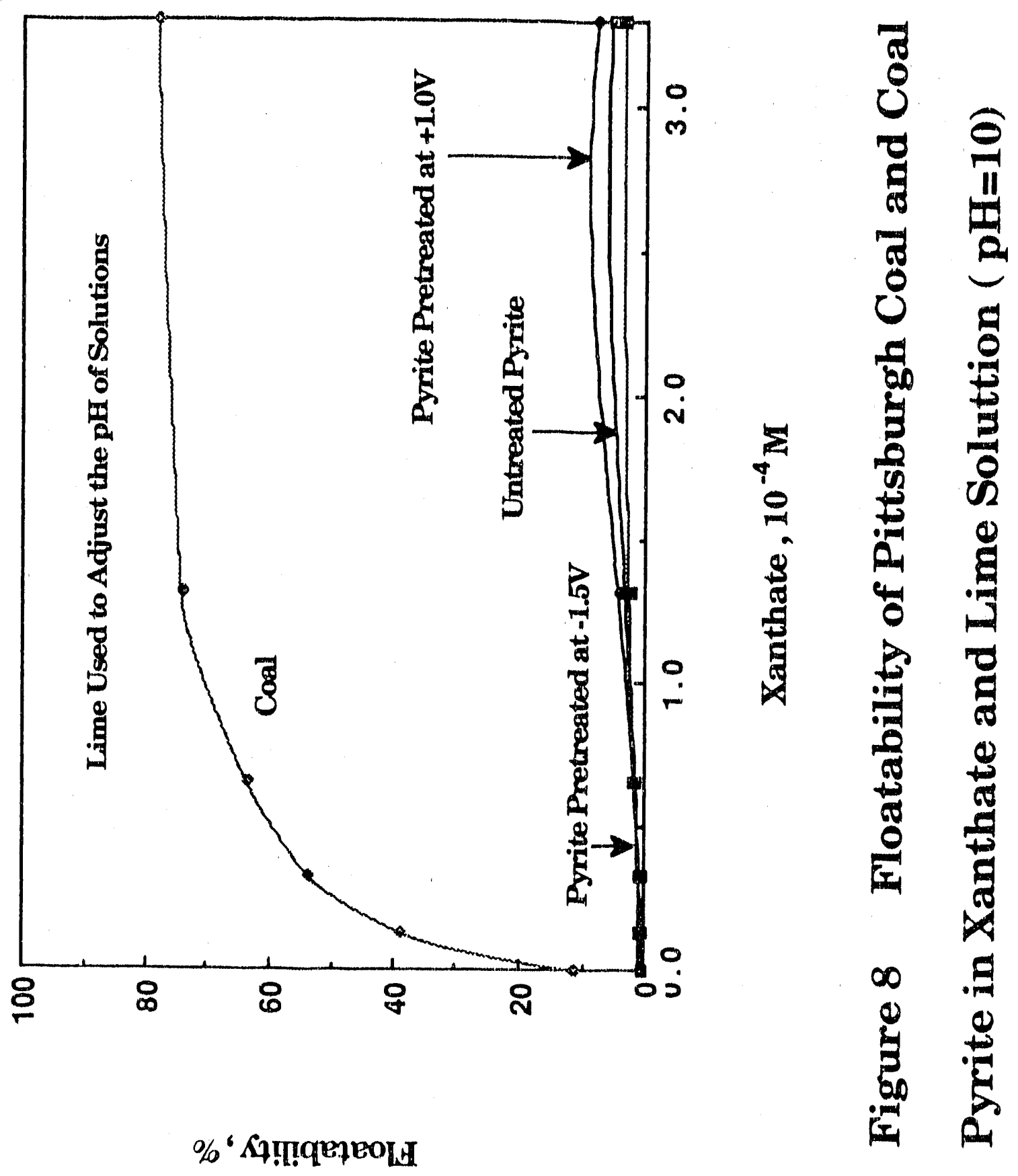




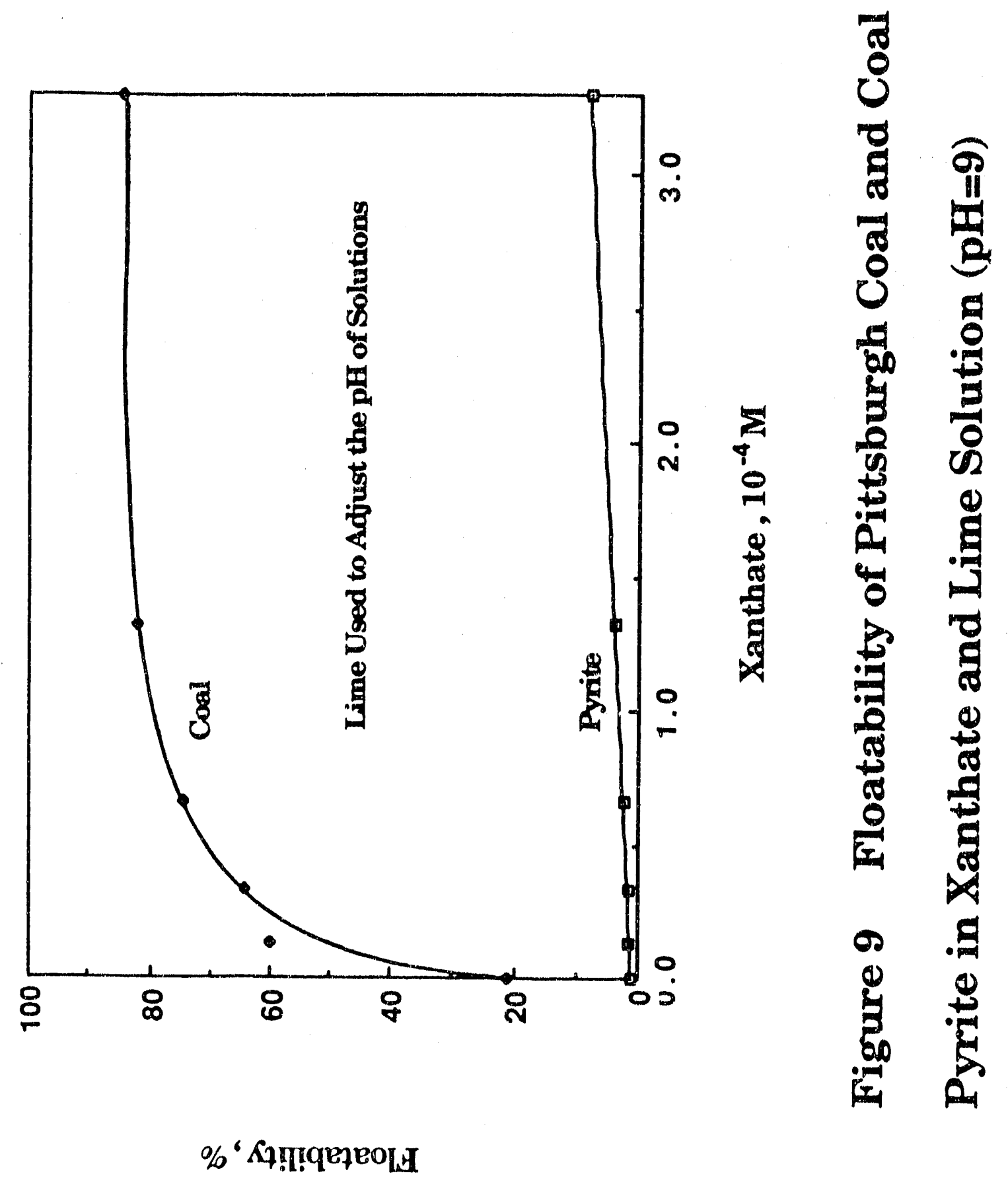




\section{FLOTATION KINETICS OF COAL AND COAL PYRITE}

\section{INTRODUCTION}

The kinetics of the coal and coal pyrite system is very important to understand and improve the coal flotation processes. Coal and pyrite have not only different floatabilities but also different flotation rates, which could be utilized in the separation of coal and pyrite.

Flotation kinetics tests were conducted by collecting flotation concentrates at different times, and fitting the flotation yield and time profile to a flotation kinetics model.

\section{RESULTS AND DISCUSSION}

Flotation results of Pittsburgh No. 8 coal and coal pyrite with xanthate as collector are given at Table 1. Floatation results of Pittsburgh No. 8 coal with dodecane as collector are found in Table 2.

The flotation kinetics results were fitted by the proportionality law of flotation kinetics proposed by Dr. Ralph Lai of the DOE Pittsburgh Energy Technology Center $(1,2)$. The mathematical form of this flotation kinetics law is given by equation 1 .

$$
\frac{d r}{d t}=K \frac{\left(R_{1}-R\right)}{t}
$$

It states that the rate of recovery $\mathrm{R}$ of floatable materials is proportional to the amount of floatable materials remaining to be recovered, $\left(R_{i}-R\right)$, and is inversely proportional to flotation time, $t, R_{i}$ is the ultimate recovery at infinite time, and $K$ is the flotation rate constant. In the integrated form, the equation becomes: 


$$
\ln \left[\frac{1}{\left(R_{1}-R\right)}\right]=\ln (t)+\ln (C)
$$

in which $c$ is equal to $1 /\left[R_{1}-R(1)\right]$ and $R(1)$ is cumulative recovery after one minute of flotation. If the flotation process follows the proportionality law, a log-log plot of $1 /(\mathrm{Ri}$ $R$ ) versus $t$ should be a straight line with slope of $K$. In this study the $\log -\log$ plot and a non linear fitting program were used to find the parameters of the proportionality law of flotation kinetics.

Table 1 Flotation Yield of Pittsburgh No 8 Coal and Coal Pyrite at Different Floatation Times With Xanthate

\begin{tabular}{||c|c|c|c|c||}
\hline \multirow{2}{*}{$\begin{array}{c}\text { Flotation } \\
\text { Time }\end{array}$} & \multicolumn{4}{|c||}{ Xanthate (M) } \\
\cline { 2 - 5 } & \multicolumn{2}{|c|}{ Coal } & \multicolumn{2}{c||}{ Pyrite } \\
\hline minutes & 0.0 & $2.5 \times 10^{-6}$ & 0.0 & $2.5 \times 10^{-6}$ \\
\hline 1.0 & 11.25 & 41.42 & 1.53 & 6.66 \\
\hline 3.0 & 22.05 & 71.20 & 3.54 & 9.67 \\
\hline 5.0 & 31.54 & 83.40 & 4.55 & 12.45 \\
\hline 10.0 & 42.25 & 92.99 & 5.27 & 15.56 \\
\hline 15.0 & 45.73 & 94.99 & 8.48 & 17.78 \\
\hline 30.0 & 51.23 & 96.99 & 9.59 & 22.54 \\
\hline
\end{tabular}

Figures 1 and 2 show the experimental data and model-fitted data for Pittsburgh coal and coal pyrite respectively, with xanthate as collector. It can be seen from these figures that the test data follows the proportionality law for the tested conditions.

Figure 3 shows the experime tal data for Pittsburgh Coal at long flotation time with dodecane as collector. It can be seen that 80 percent of coal was floated in the first several 
Table 2 Flotation Yield of Pittsburgh No. 8 Coal at Different Floatation Times With Dodecane

\begin{tabular}{|c|c|c|c|c||}
\hline \multirow{2}{*}{$\begin{array}{c}\text { Flotation } \\
\text { Time }\end{array}$} & \multicolumn{4}{|c||}{ Dodecane $(\mathrm{ml} / \mathrm{)})$} \\
\cline { 2 - 5 } & \multicolumn{2}{|c|}{ Coal } & \multicolumn{2}{c||}{ Pyrite } \\
\hline minute & 0.0 & 0.032 & 0.065 & 0.130 \\
\hline 1.0 & 12.10 & 15.25 & 19.25 & 22.56 \\
\hline 2.0 & 24.91 & 29.90 & 38.45 & 38.31 \\
\hline 4.0 & 41.62 & 44.77 & 54.03 & 62.11 \\
\hline 8.0 & 54.49 & 63.61 & 64.87 & 78.81 \\
\hline 16.0 & 73.40 & 77.07 & 81.86 & 90.72 \\
\hline 32.0 & 23.86 & 86.15 & 89.77 & 96.01 \\
\hline 64.0 & 90.56 & 91.25 & 92.51 & 99.41 \\
\hline 96.0 & 93.21 & 94.25 & 95.42 & 99.75 \\
\hline
\end{tabular}

minutes.

Figures 4-7 give the $\log -\log$ plots of $1 /\left(R_{i}-R\right)$ versus $t$ for Pittsburgh No. 8 coal with different dosages of dodecane. It seems that for all cases tested a straight line was produced and the data follow the proportionality law of flotation kinetics.

\section{REFERENCES}

1. Ralph W. Lai, "How to Obtain More Information Out of Flotation Data", 1982, Trans. AIME, Vol. 272, pp. 1989-1993.

2. Ralph W. Lai, "Get More Information from Flotation Data", 1981, Chem. Eng., October, pp. 181-182. 


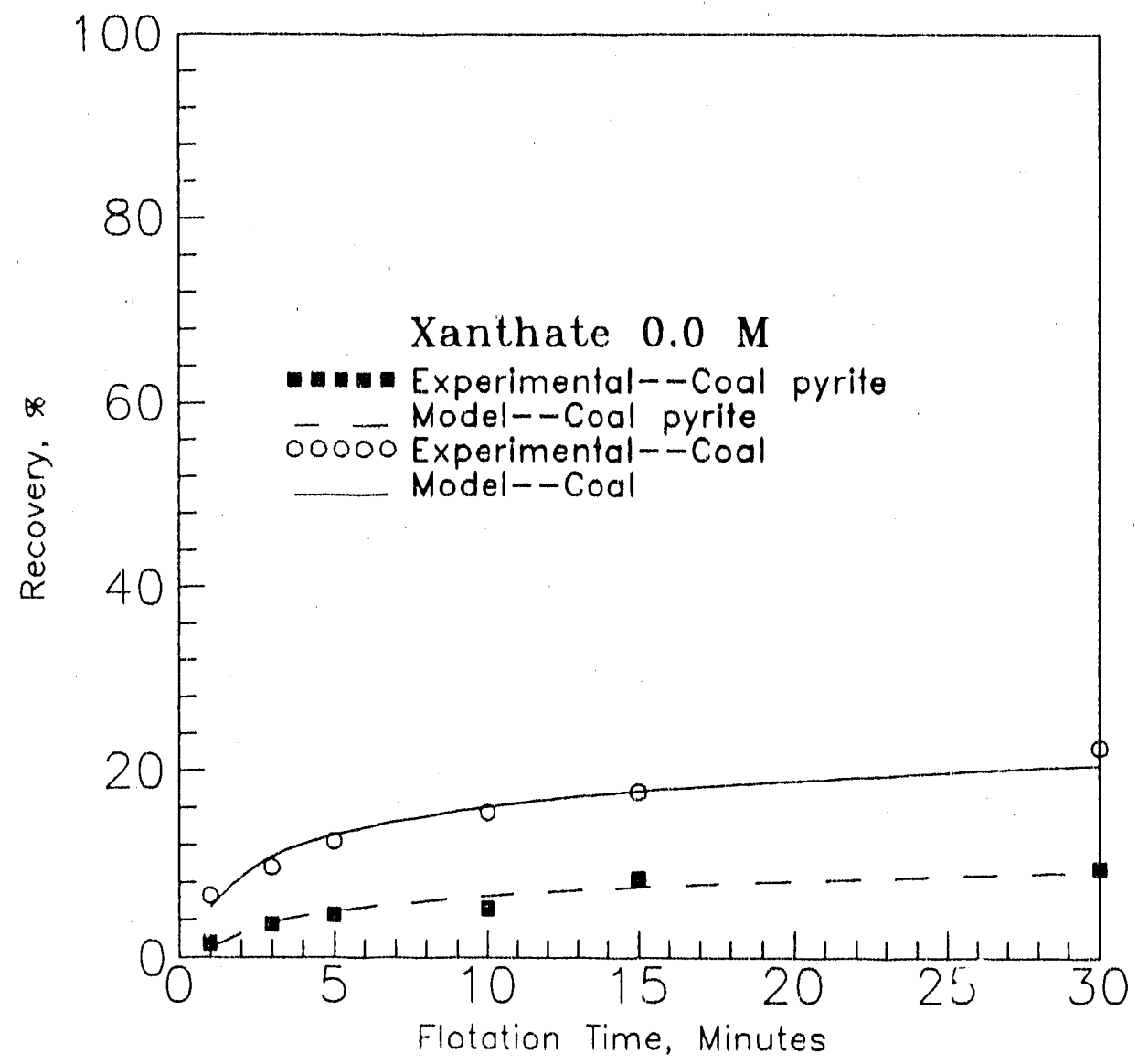

Figure 1 Kinetics of Pittsburgh No 8 Coal and Coal Pyrite with Xanthate as Collector 


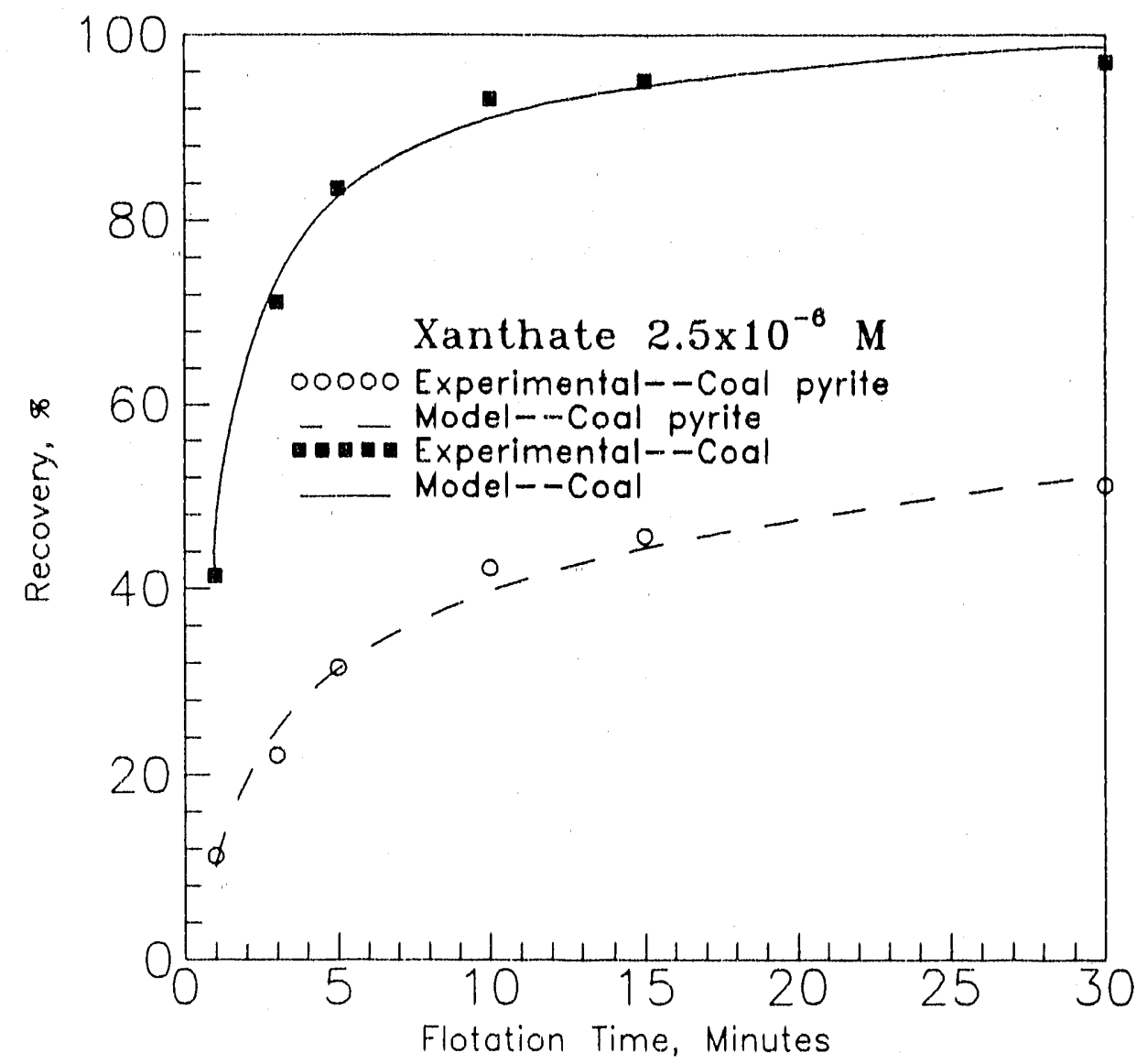

Figure 2 Kinetics of Pittsburgh No 8 Coal and Coal Pyrite with Xanthate as Collector 


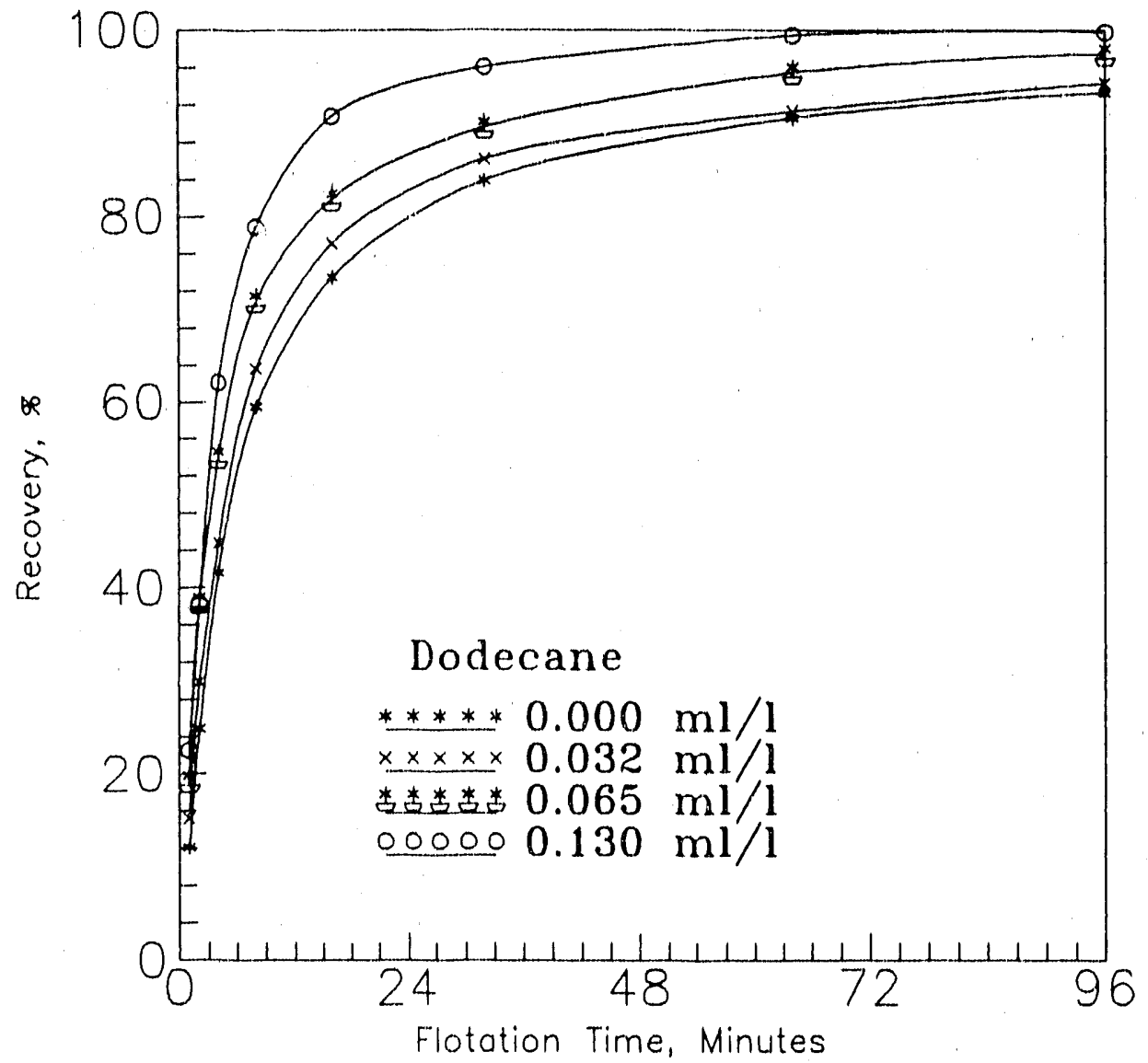

Figure 3 Kinetics of Pittsburgh No 8 Coal Flotation with Dodecane as Collector 


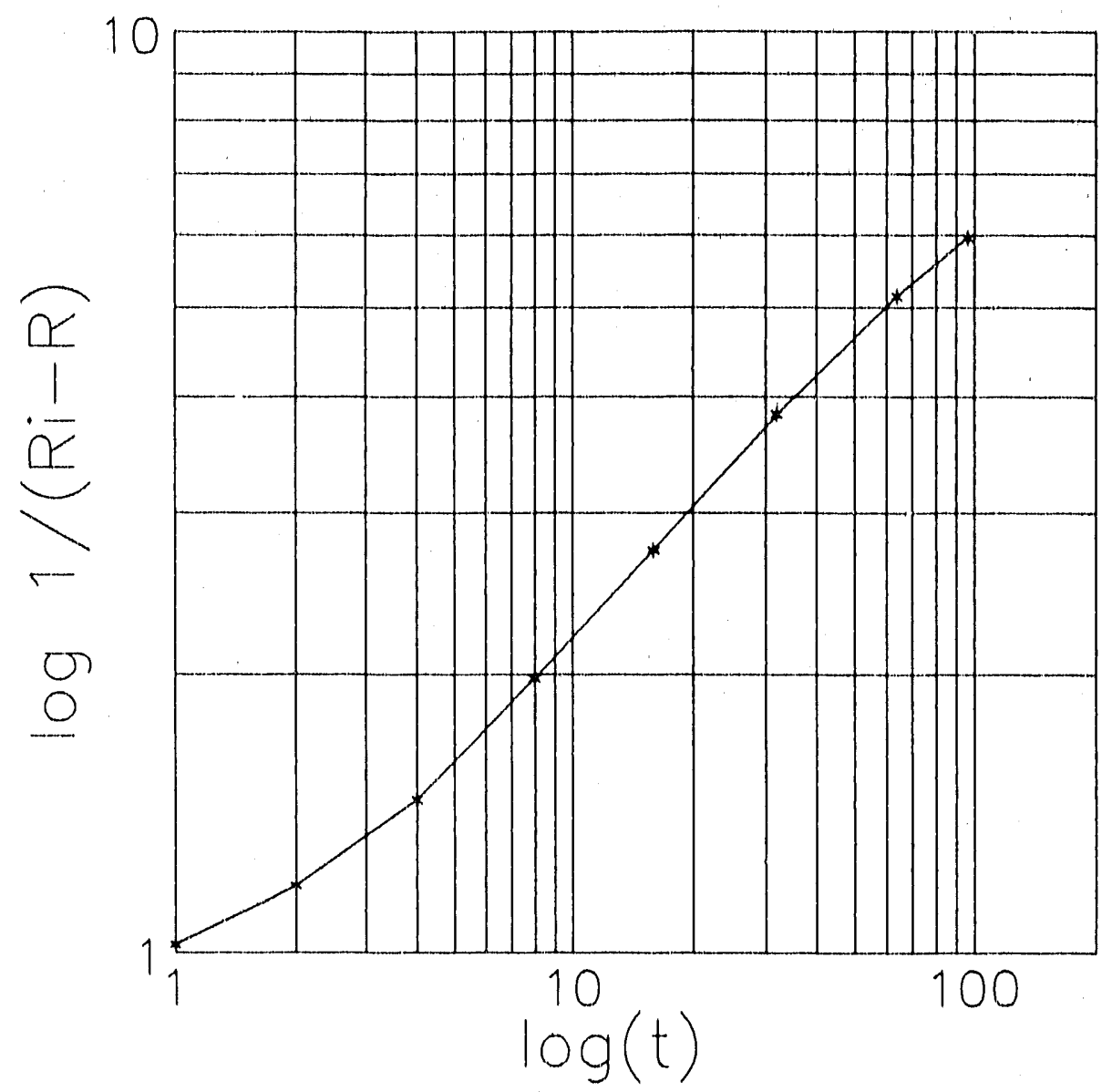

Figure $4 \log (1 /(r i-r))$ vs $\log (t)$ for Pittsburgh No 8 coal Dodecane: $0.0 \mathrm{ml} / \mathrm{l}$ 


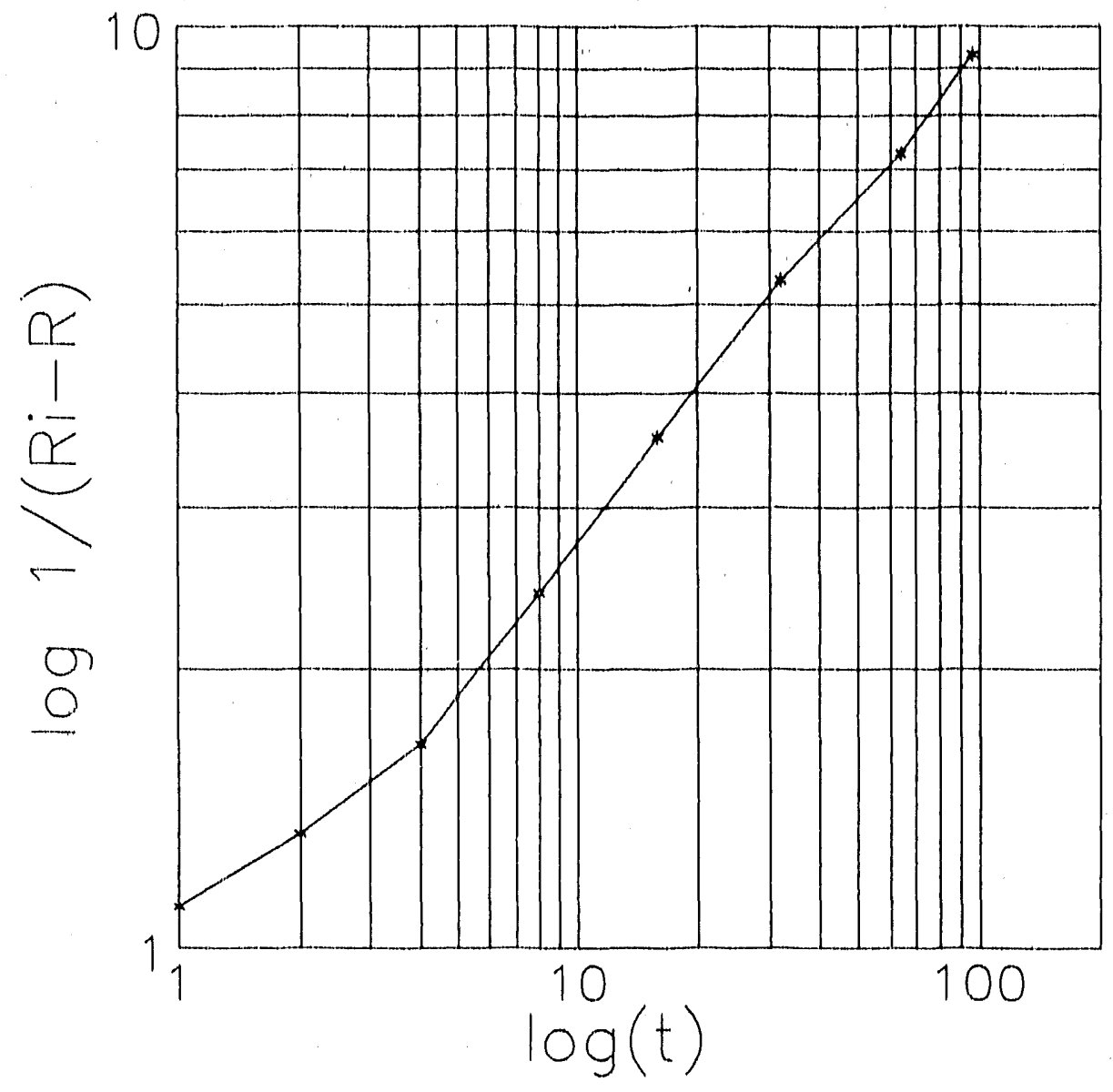

Figure $5 \log (1 /(r i-r))$ vs $\log (t)$ for Pittsburgh No 8 coal Dodecane: $0.032 \mathrm{ml} / \mathrm{l}$ 


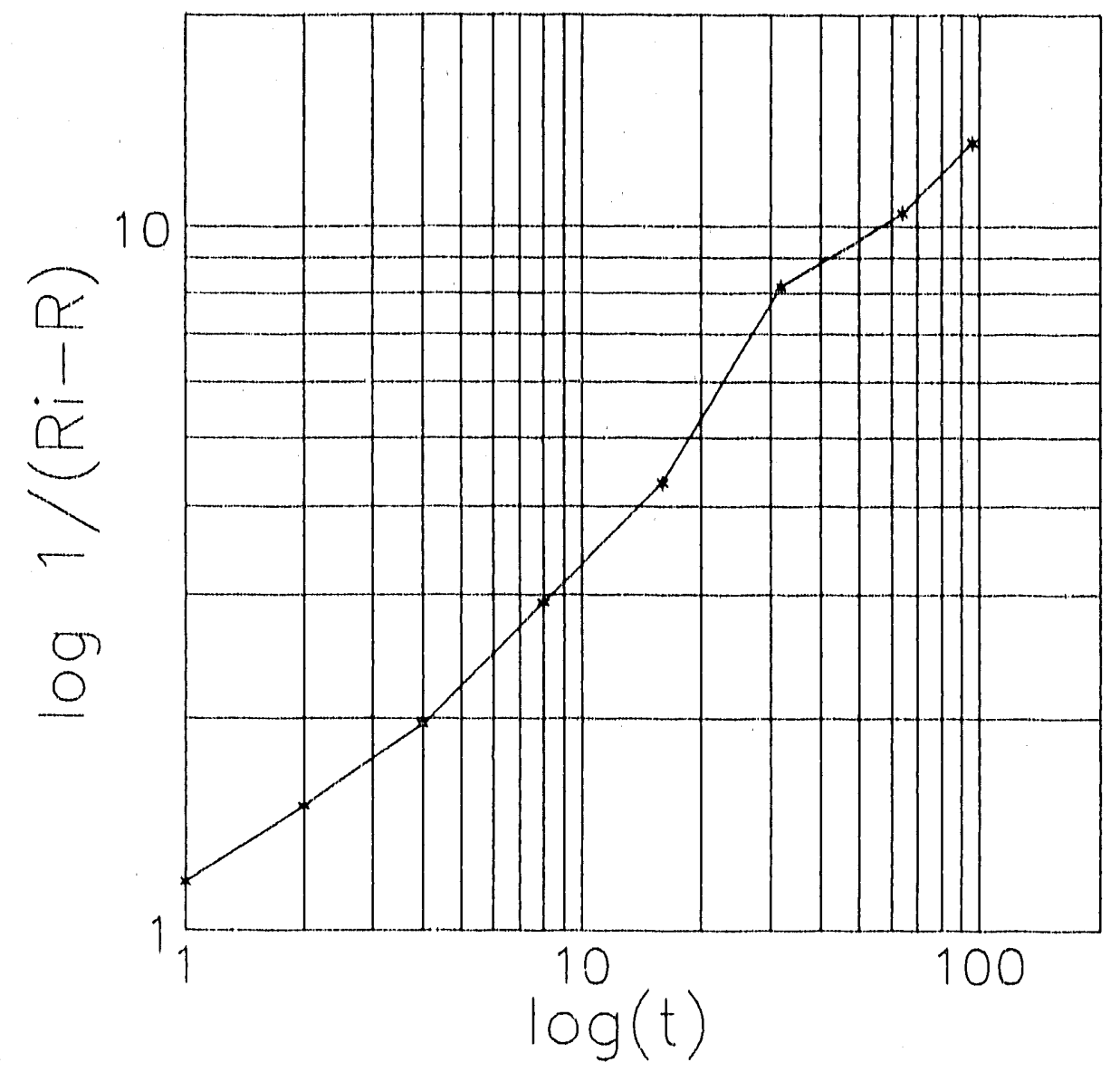

Figure $6 \log (1 /(r i-r))$ vs $\log (t)$ for Pittsburgh No 8 coal Dodecane: $0.065 \mathrm{ml} / \mathrm{l}$ 


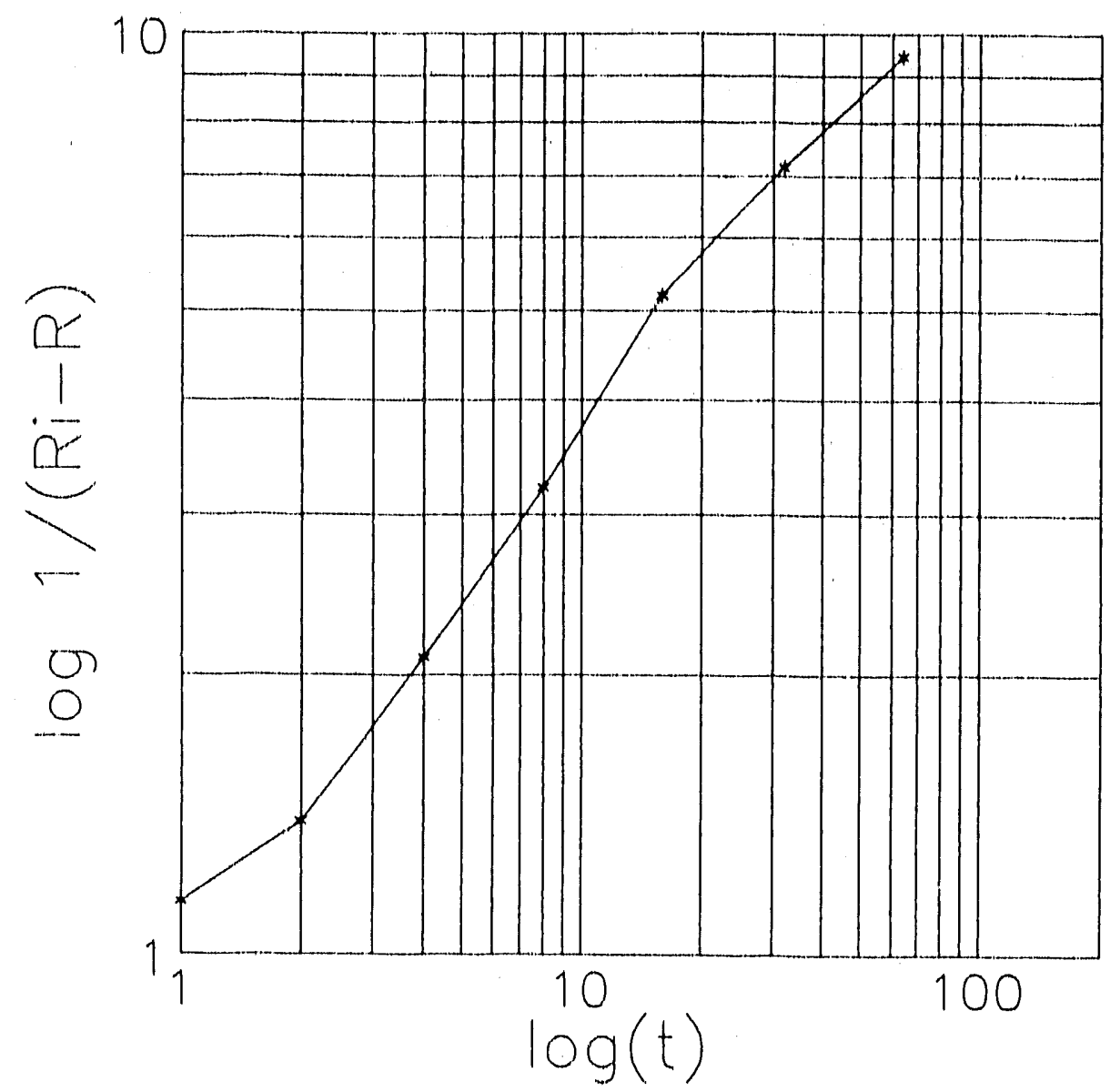

Figure $7 \log (1 /(r i-r))$ vs $\log (t)$ for Pittsburgh No 8 coal

Dodecane: $0.132 \mathrm{ml} / \mathrm{l}$ 

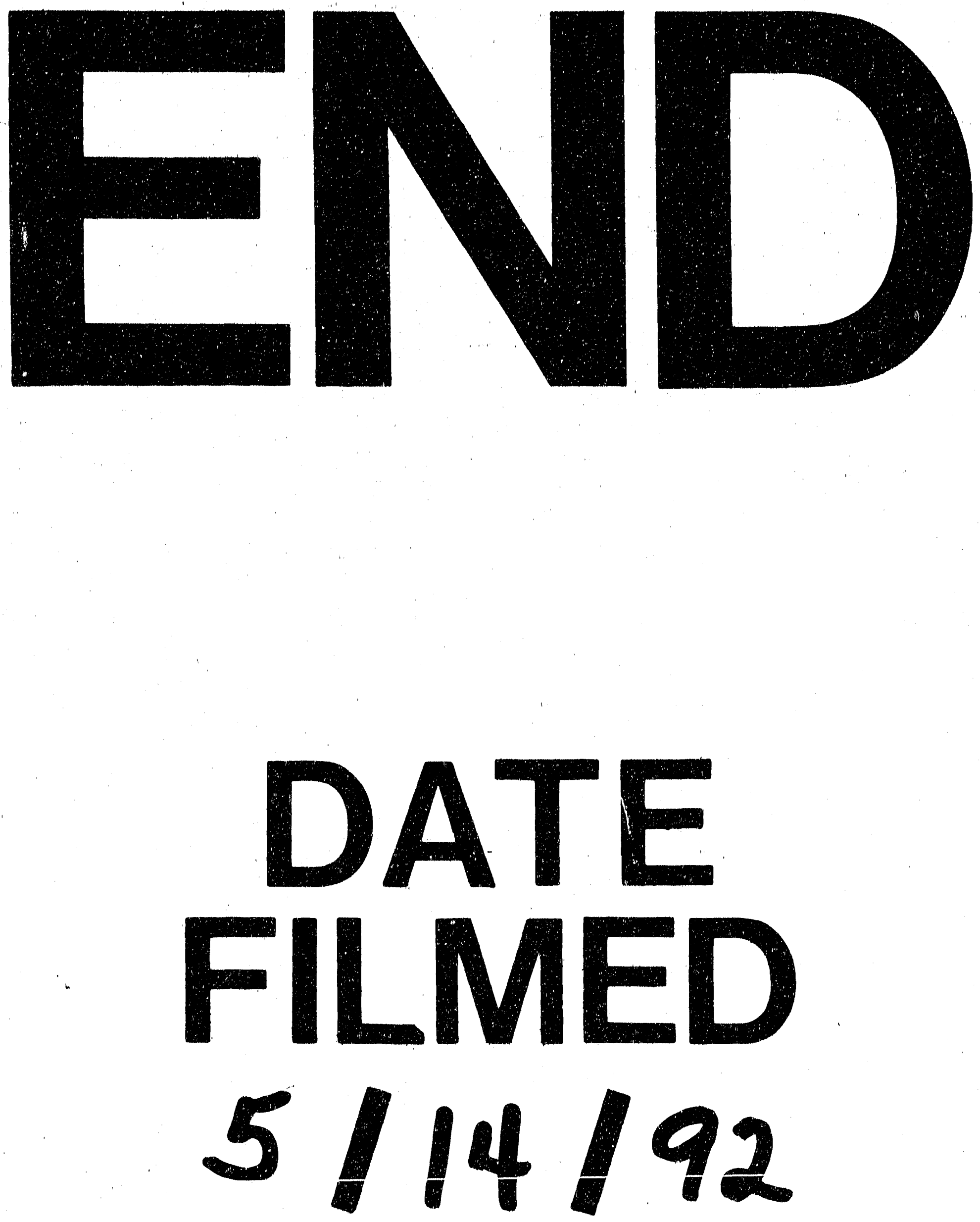
- 